Florida International University

FIU Digital Commons

$9-5-2018$

\title{
Habitat Use of Three Abundant Predatory Fish Species in the Freshwater Marshes of the Florida Everglades
}

Alex T. Ontkos

Florida International University, aontk001@fiu.edu

Follow this and additional works at: https://digitalcommons.fiu.edu/etd

Part of the Terrestrial and Aquatic Ecology Commons

\section{Recommended Citation}

Ontkos, Alex T., "Habitat Use of Three Abundant Predatory Fish Species in the Freshwater Marshes of the Florida Everglades" (2018). FIU Electronic Theses and Dissertations. 3873.

https://digitalcommons.fiu.edu/etd/3873

This work is brought to you for free and open access by the University Graduate School at FIU Digital Commons. It has been accepted for inclusion in FIU Electronic Theses and Dissertations by an authorized administrator of FIU Digital Commons. For more information, please contact dcc@fiu.edu. 


\title{
FLORIDA INTERNATIONAL UNIVERSITY
}

\author{
Miami, Florida
}

\section{HABITAT USE OF THREE ABUNDANT PREDATORY FISH SPECIES IN THE FRESHWATER MARSHES OF THE FLORIDA EVERGLADES}

\author{
A thesis submitted in partial fulfillment of the \\ requirements for the degree of \\ MASTER OF SCIENCE \\ in \\ BIOLOGY \\ by
}

Alex T. Ontkos

2018 
To: Dean Michael R. Heithaus

College of Arts, Sciences and Education

This thesis, written by Alex T. Ontkos, and entitled Habitat Use of Three Abundant Predatory Fish Species in the Freshwater Marshes of the Florida Everglades, having been approved in respect to style and intellectual content, is referred to you for judgment.

We have read this thesis and recommend that it be approved.

Michael R. Heithaus

Yannis P. Papastamatiou

Joel C. Trexler, Major Professor

Date of Defense: September 5, 2018

The thesis of Alex T. Ontkos is approved.

Dean Michael R. Heithaus

College of Arts, Science, and Education

Andrés G. Gil

Vice President for Research and Economic Development and Dean of the University Graduate School

Florida International University, 2018 


\section{DEDICATION}

This thesis is dedicated to my brother and nephew.

Many of my fondest memories are of time spent in the Everglades with you. I

hope Hudson gets to experience the vast, intricate richness that we have grown

to love. 


\section{ACKNOWLEDGMENTS}

I would like to thank the many graduate students and field technicians of the Trexler lab who assisted with this project in any way. There are many individuals who participated in the radio-tracking efforts that made this project possible. Tina Van Doornik, Erica Ascani, and Tom Granger braved mosquito swarms, countless thunderstorms, and sleepless nights while assisting with the 24-hour tracking portion of this project. I have many fond memories of our time on the L67-C; I am appreciative of their amity and commitment. I am also grateful for my many discussions with Mike Bush, who contributed to this work while conducting his own dissertation research. I would also like to thank Bradley Strickland and Abraham Smith for their companionship, insight, and encouragement through the years. I would like to express my gratitude towards Daniel Gann and Brittany Harris for their outstanding contribution to this project. Their efforts enhanced the mapping portion of this project and I am grateful for their time, extensive knowledge, and dedication. I would also like to thank my Major Professor, Joel Trexler, for his support and well-timed humor. This project was funded by the United States Geological Survey under Cooperative Agreement G10AC00409. 


\author{
ABSTRACT OF THE THESIS \\ HABITAT USE OF THREE ABUNDANT PREDATORY FISH \\ SPECIES IN THE FRESHWATER MARSHES OF THE FLORIDA \\ EVERGLADES \\ by
}

Alex T. Ontkos

Florida International University, 2018

Miami, Florida

Professor Joel C. Trexler, Major Professor

The Florida Everglades presents a model setting for studying animalhabitat relationships in a dynamic landscape that is heavily influenced by seasonal hydrology and water management. I used dynamic, high-resolution habitat classification maps and radio-telemetry to examine habitat preference of Largemouth Bass, Bowfin, and Florida Gar before and after a field-scale manipulation was established to address uncertainties with Everglades restoration and water management practices. Results indicate preference for the canal habitat by all three species, which represents only a small portion of the submerged landscape even in the driest conditions. Bowfin and Florida Gar were more likely to be relocated within marsh habitats than Largemouth Bass. Preference for the canal habitat increased after landscape alteration and was influenced by water management practices rather than hydrological or environmental factors. Partial canal backfilling may assist with accomplishing 
restoration goals while maintaining preferred habitat for economically and ecologically valuable predatory fishes. 


\section{TABLE OF CONTENTS}

CHAPTER

PAGE

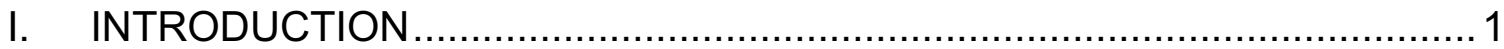

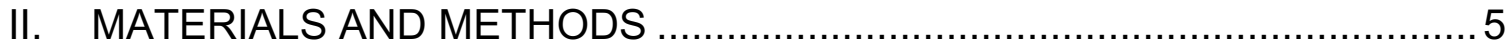

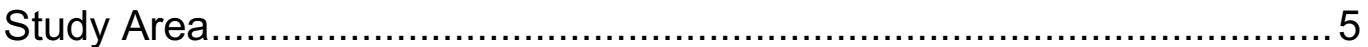

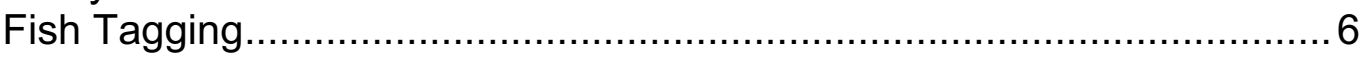

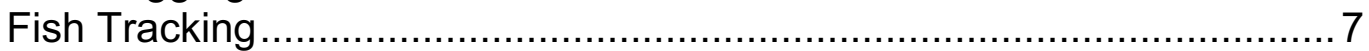

Measuring Habitat Use and Availability for Fish Locations ..................... 8

Statistical Methods and Analyses................................................... 11

Habitat Preference............................................................. 11

Movement Behavior............................................................... 13

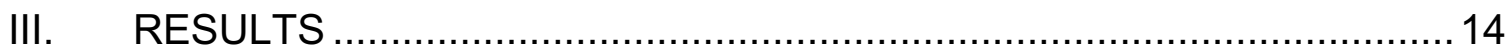

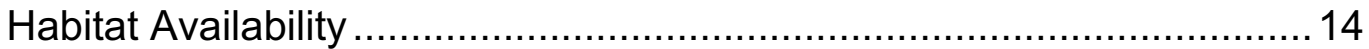

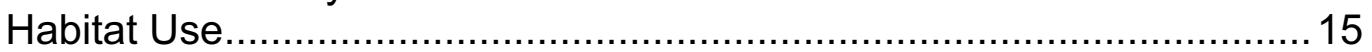

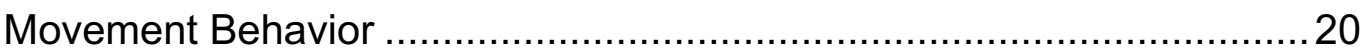

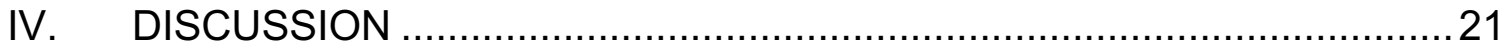

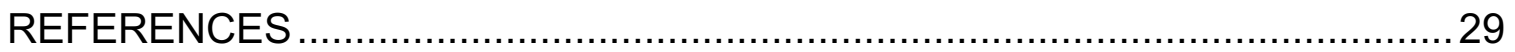

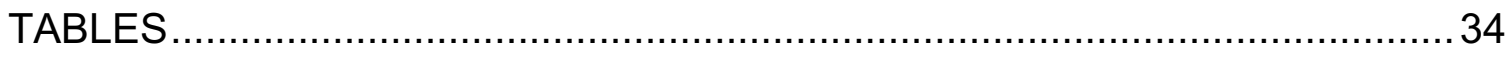

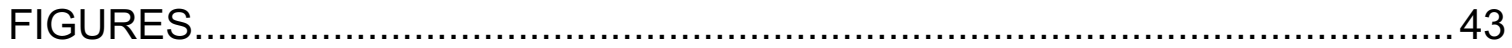

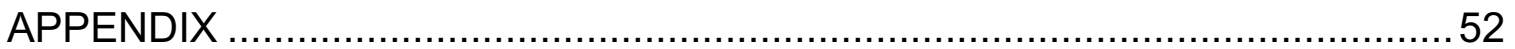




\section{LIST OF TABLES}

TABLE

PAGE

Table 1. Mean number of relocations and days at large for each species over the course of the weekly telemetry study.....

Table 2. Number of individuals of LMB and Florida Gar radio-tracked during each 24-hour tracking session from June 2016 through April 2017

Table 3. Distance of availability radii used to determine habitat proportions for each species for habitat use analyses

Table 4. Percent of weeks each habitat class was preferred based on 100-m and species-specific availability selection ratio calculations

Table 5. Results of Kruskal-Wallis tests used to determine if significant differences exist between selection ratio calculations using 100-m and species-specific availability radii

Table 6. Results of generalized linear mixed-effects models of factors affecting canal selection ratios for LMB, Bowfin, and Florida Gar

Table 7. Effects of environmental, hydrological, and water management predictor variables on the variability of canal selection ratios for each species. Only models with $\triangle \mathrm{AICc}$ values $<2$ are shown

Table 8. Results of generalized linear mixed-effects models of factors affecting diel ROM for LMB and Florida Gar.

Table 9. Significance of season and time of day on ROM for LMB and Florida Gar for generalized linear mixed-effects models. Results are only given for models with lowest Pseudo-AICc scores 


\section{LIST OF FIGURES}

FIGURE

PAGE

1. A) Map of South Florida demonstrating the geographic location of the study area; B) Map of DPM study area with water management features and spatial arrangement of habitat classes. Spatial resolution of pixels is $2 \mathrm{~m}$....44

2. A) Hydrograph of daily median water depth for representative graminoid marshes in the Gap and WCA-3B; B) Mean proportion of available habitat that was in the canal class for tagged fish population reported separately by species; C) Proportion of tagged fish in canal habitat reported separately by species; D) Population-level selection ratio for canal habitat versus time reported separately by species

3. Representative time-series of habitat classification maps for a portion of the study area demonstrating intra-annual change in habitat availability from November 2014 to October 2015. Spatial resolution of pixels is $2 \mathrm{~m}$.

4. Bar chart illustrating percent of radio-telemetry relocations in most used habitat classes reported separately by season

5. Step-length frequency distributions for weekly telemetry data

6. Step-length frequency distributions for diel telemetry data

7. Rate of movement (ROM) for LMB, Bowfin, and Florida Gar based on weekly tracking data. An * indicates a significant $(p<0.05)$ intraspecific difference in ROM between seasons. For each season, bars with a letter in common are not significantly different. Error bars indicate $95 \%$ confidence intervals

8. A) Map demonstrating movement patterns of Florida Gar LP03 and Florida Gar LP08 from November 2015-September 2016. Movements for both fish were confined to relatively small ranges. LP03 resided primarily in marsh habitats while LP08 resided within the canal or in adjacent marshes; B) Map demonstrating movements of Florida Gar LP16 from January 2016August 2016. LP16 used all habitats except the sawgrass-cattail marsh class. Lines between sequential location points indicate Euclidean path 


\section{ABBREVIATIONS AND ACRONYMS}

$\begin{array}{ll}\text { ANOVA } & \text { Analysis of Variance } \\ \text { CERP } & \text { Comprehensive Everglades Restoration Plan } \\ \text { DEM } & \text { Digital Elevation Model } \\ \text { DPM } & \begin{array}{l}\text { Decompartmentalization and Sheetflow Enhancement Physical } \\ \text { Model }\end{array} \\ \text { EDEN } & \text { Everglades Depth Estimation Network } \\ \text { FWC } & \text { Florida Fish and Wildlife Conservation Commission } \\ \text { GLMM } & \text { Generalized Linear Mixed-Effects Model } \\ \text { LMB } & \text { Largemouth Bass } \\ \text { ROM } & \text { Rate of Movement } \\ \text { SFWMD } & \text { South Florida Water Management District } \\ \text { SL } & \text { Standard Length } \\ \text { USACE } & \text { United States Army Corps of Engineers }\end{array}$




\section{INTRODUCTION}

The distribution of submerged habitats within ephemeral wetlands is often dynamic and spatially heterogeneous (Ulrich 2005), suggesting that aquatic organisms must adopt strategic behavior to avoid desiccation. For instance, some aquatic beetles and odonate nymphs in freshwater wetlands burrow into benthic substrates to avoid desiccation and ensure rapid colonization after reinundation (Batzer and Wissinger 1996). Reptiles, such as the copperbelly water snake Nerodia erythrogaster neglecta, demonstrate extension of home ranges during periods of wetland expansion (Roe et al. 2004). Changes in the dispersal behavior of fish associated with variation in hydrology have been well documented in river floodplains and ephemeral wetlands around the world (Kwak 1988, Winemiller and Jepsen 1998, Rayner et al. 2008, Kerezsy et al. 2013). Animal behavior in seasonally pulsed wetland ecosystems is intimately connected with water availability and landscape pattern (Parkos and Trexler 2014). Ephemeral wetland ecosystems present an opportunity to examine the nature of animal-habitat relationships in a dynamic landscape.

Studying animal-habitat relationships provides insight into the biological requirements of species and allows us to determine the ecological factors that contribute to their persistence (Beyer et al. 2010). Additionally, studying habitat use is valuable for implementing successful conservation initiatives and projecting the effects of habitat alteration on species (Manly et al. 2002). Studying animal-habitat relationships may prove particularly important for 
wetlands and their associated biota, which have faced dramatic losses in the preceding centuries as a result of anthropogenic disturbances including dredging, draining, and filling (Johnson 1994, Gibbs 2000). The natural complexity of these systems can be compounded by the existence of anthropogenic structures, such as dams and roadways, that can impact the dispersal of aquatic organisms across the landscape (Pépino et al. 2012, Braaten et al. 2015).

The freshwater marshes of the Florida Everglades present a model setting for studying habitat use in a dynamic landscape altered by human activities. Historically, the Florida Everglades was a spatially extensive, unimpeded wetland extending from the southern shore of Lake Okeechobee southward to Florida Bay. Rainfall and water flowing from Lake Okeechobee played a vital role in providing the northern and downstream Everglades with freshwater inflow (McVoy et al. 2011). Aquatic communities of the freshwater Everglades continue to be influenced by an annual wet-dry precipitation cycle. The wet season is marked by abundant localized rainfall in May-October leading to maximum marsh water depths late in the season. The dry season typically occurs in NovemberApril when the frequency and magnitude of rainfall events decreases. Interannual variability in rainfall plays an important role in the overall hydrological regime of the Everglades ecosystem (DeAngelis 1994).

The freshwater marshes of the Everglades are also characterized by a braided mosaic of vegetation communities. The pre-drainage landscape was dominated by a ridge-and-slough structure oriented parallel to the gentle southward flow of water from Lake Okeechobee (Larsen et al. 2011). Ridges are 
dominated by dense, rhizomatous sawgrass Cladium jamaicense and have a relatively high stem density. Spikerush Eleocharis cellulosa and water hyssop Bacopa caroliniana may also be found in sparse sawgrass ridges but are not dominant (Gunderson 1994). Sloughs are relatively open areas with little emergent vegetation, often dominated by white water lily Nymphaea odorata, floating hearts Nymphaea aquatica, and spatterdock Nuphar advena. Graminoid marshes, or wet prairies, are also common across the Everglades landscape. Graminoid marshes are often comprised of spikerush, beakrush Rhynchospora tracyi, maidencane Panicum lanceolata, or arrowhead Sagittaria lancifolia.

The topography associated with vegetation communities and seasonal variation in rainfall interact to influence water availability within habitats. For instance, sawgrass ridges are relatively shallow and experience a higher frequency of drying events than wet prairies and sloughs (Jordan et al. 1997). In contrast, sloughs are less prone to drying and often remain inundated during the dry season (Jordan et al. 1997, McVoy et al. 2011). The ecology of the Everglades is intimately connected with this "spatially dynamic hydropattern" as it affects both abiotic and biotic processes (DeAngelis 1994). Hydrological disturbances (when the marsh surface is exposed by receding water) influence the population dynamics of both small and large fish (standard length $>8 \mathrm{~cm}$ ) communities across the Everglades landscape (Chick et al. 2004, Ruetz et al. 2005, Parkos et al. 2011).

While the vegetative mosaic of the historical Everglades remains largely intact over much of the ecosystem, the overall landscape has been drastically 
altered to accommodate the societal needs of a growing populace in South Florida (Light and Dineen 2004). A vast canal and levee network, consisting of $>2,400 \mathrm{~km}$ of canals and $>1,600 \mathrm{~km}$ of earthen levees (SFWMD 2010), has compartmentalized areas of the Everglades into water impoundment regions. These structures have altered the natural hydrology of the Everglades (Light and Dineen 2004, NRC 2012) and create an artificial spatial scale for aquatic organisms (Chick et al. 2004). Compartmentalization and water management may have led to a gradual decrease in landscape heterogeneity (i.e., gradual loss of ridge-and-slough structure) in some regions (Larsen et al. 2011). In an attempt to restore the natural hydrology of the Everglades and reduce the impact of water management practices, the Comprehensive Everglades Restoration Plan (CERP) was enacted in 2000 as a joint operation between the United States Army Corps of Engineers (USACE) and South Florida Water Management District (SFWMD) (NRC 2012). Sheetflow restoration, levee removal, and canal backfilling are key components of CERP (USACE and SFWMD 1999), however, the impact of these efforts on the ecology of the Everglades remains uncertain.

The objective of this study is to determine how the trajectory of Everglades restoration will affect the habitat use of large-bodied piscivorous fish in the freshwater marshes of the Everglades. To do this, I studied the movement of three abundant large fish species before and after an experimental manipulation of habitat connectivity and introduction of flowing water into an area lacking flow and divided by a canal and levee for over 60 years. Largemouth Bass Micropterus salmoides (hereafter referred to as LMB), Bowfin Amia calva, and 
Florida Gar Lepisosteus platyrhincus are the most abundant large-bodied piscivorous fishes in the freshwater Everglades (Chick et al. 2004). The lifespan of these species exceeds the duration of the annual wet-dry cycle, requiring them to alter their habitat use as the availability of suitable habitat fluctuates. I used radio-telemetry and dynamic, high-resolution habitat classification maps to determine which vegetation communities were preferred or avoided before and after experimental landscape alteration. I determined if environmental factors or water management practices affected habitat preference of these species. I used the results of this study to assess how planned restoration will impact ecological processes and recreational fisheries.

\section{MATERIALS AND METHODS}

\section{Study Area}

Fish tagging and radio-telemetry were primarily conducted in an area of the Everglades located between the L67-A and L67-C levees known as "The Gap" (Figure 1A). Beginning two years into this study, this area was subjected to controlled water deliveries as part of the Decompartmentalization and Sheet Flow Enhancement Physical Model (DECOMP or DPM). The DPM project is a pilot project of the Comprehensive Everglades Restoration Plan (CERP) to address ecological uncertainties associated with sheetflow restoration and canal backfilling. As part of the DPM project, ten gated $1.54 \mathrm{~m}$ (60-inch) culverts (known as the S-152 culverts) were constructed on the L67-A levee to allow for controlled water deliveries into the DPM study area early in the South Florida dry 
season, November-January. The first flow event associated with the DPM project was initiated in November 2013. The L67-C canal was altered to accommodate three $304.8 \mathrm{~m}$ (1,000 foot) canal backfilling treatments (filled to surrounding marsh depth, approximately $1 / 2$ original canal depth, and no backfilling). A $914 \mathrm{~m}$ section of the L67-C levee was used to fill the adjacent L67-C canal to restore hydrological and biological connectivity between the Gap and WCA-3B (NRC 2012). Levee removal created a potential corridor for fish movement between the two WCAs; an additional corridor was opened in June 1994, approximately 8 km northeast, where a portion of the L67-C levee was removed. Fish movements were bounded in the west by the L67-A levee, in the south by the L-29 levee, in the east by the L-30 levee, and in the north by the C-304 levee (Figure 1B). The study area had a vegetation landscape consisting of a mosaic of emergent tree islands, sawgrass ridges, sloughs, and wet prairies representative of the Everglades landscape. Seasonal water-level fluctuation made the aquatic phase of this landscape quite dynamic.

\section{Fish Tagging}

Fish were tagged in a series of nine batches, beginning with LMB and Bowfin in May 2011 (Appendix 1). Tagging of Bowfin ceased in November 2015 to allow for tagging of Florida Gar. Fish were collected by airboat electrofishing (Chick et al. 1999). An equal number of fish were tagged in marsh and canal habitats. After capture, fish were placed in an aerated tub containing ambient water and 100-132 mg/L tricaine methanesulfonate (MS-222, Tricaine-S, Western Chemical, Inc.). Fish remained in the MS-222 bath until they lost equilibrium 
(mean=6.3 minutes, range=1-33 minutes, Appendix 1), then were measured for length and placed on a damp sponge to prepare for tag implantation surgeries.

For LMB and Bowfin, radio-tags (PD-2 and RI-2B, 2.9-8.5 g, Holohil Systems, Ltd.) were inserted into a $2-4 \mathrm{~cm}$ incision made lateral-anterior of the vent. Florida Gar were only tagged with RI-2B tags (7.9-8.5 g), which were inserted central-posterior of the pelvic girdle. Incisions were closed with 2-5 nonabsorbable interrupted sutures (Ethicon Inc., Prolene ${ }^{\mathrm{TM}}$, Polypropylene monofilament, 3-0). The gills of fish were periodically flushed with aerated water containing MS-222 during the tagging process; mean surgery time across species was 6.31 minutes (range=3-19 minutes, Appendix 1). Fish recovered in an aerated tub of ambient water prior to release (mean recovery time $=5.28$ minutes, range=0-39 minutes, Appendix 1); recovery was indicated by fish regaining equilibrium and exhibiting normal fin movement. Fish were released within $100 \mathrm{~m}$ of their point of capture. Minimum fish lengths were established to ensure transmitter weight did not exceed the recommended limit of $\leq 2 \%$ the body weight for any fish (Winter 1983, Mulcahy 2003). The mean standard length for tagged LMB was $33.15 \mathrm{~cm}($ range $=23-45 \mathrm{~cm}), 43.12 \mathrm{~cm}($ range $=31.5-61.5 \mathrm{~cm})$ for Bowfin, and $48.05 \mathrm{~cm}$ (range=41.7-52.6 cm) for Florida Gar (Appendix 1). Fish were not relocated for at least two weeks post-surgery to allow for recovery. A total of $140 \mathrm{LMB}, 100$ Bowfin, and 40 Florida Gar were tagged for this study.

\section{Fish Tracking}

We attempted to locate fish at weekly intervals aboard an airboat using a R-1000 receiver (Communications Specialists, Inc.) with a 5-element Yagi 
antenna. Fish locations were determined with a hand-held global positioning system (GPSMAP® 76Cx, Garmin Ltd., 3-5 m DGPS accuracy). Fish that moved to areas inaccessible by boat were triangulated using a minimum of three locations and associated bearings (LOAS, Ecological Software Solutions, LLC). Fish in remote areas were also located from a fixed-wing aircraft using a RA-2A H-antenna (Telonics, Inc.) attached to each wing strut. After conducting trials with hidden tags, mean location accuracy was determined to be $1.88 \mathrm{~m}$ (range $=0$ $4.47 \mathrm{~m}, \mathrm{n}=20$ ) from the boat and $98.47 \mathrm{~m}$ (range=22.80-179.35 $\mathrm{m}, \mathrm{n}=20$ ) from the aircraft. Estimated battery life of tags ranged from 4-12 months; fish were tracked for periods up to 54 weeks (Table 1 ).

In order to assess if diel habitat use was different from weekly observations, LMB and Florida Gar were tracked from an airboat during thirteen 24-hour tracking sessions. We attempted to relocate fish at 2-hour intervals during the 24-hour period. A total of 22 LMB and 10 Florida Gar were tracked during the diel monitoring sessions that occurred between June 2016 and April 2017 (Table 2).

\section{Measuring Habitat Use and Availability for Fish Locations}

Fish locations were overlaid onto weekly habitat classification maps generated by the FIU Geographic Information Systems Center. Vegetation was classified at a $2 \mathrm{~m} \times 2 \mathrm{~m}$ spatial resolution using atmospherically and radiometrically corrected DigitalGlobe WorldView-2 data collected November through December 2012. Habitat classes were digitized from the corrected WorldView-2 imagery and associated pixel spectral data; digitized points acted 
as training data to produce the final vegetation classification map after nine machine learning iterations. Classes included floating broadleaf plants, sparse graminoid marsh, regular graminoid marsh, sparse sawgrass marsh, intermediate density sawgrass marsh, dense sawgrass marsh, cattail dominant graminoid marsh, sawgrass-cattail marsh (50-75\% C. jamaicense and Typha spp.), herbaceous marsh, shrub/herbaceous marsh, shrubs and trees, and canal. Canal and levee features were digitized as polygons and rasterized for the final habitat classification map (Figure 1B). For habitat use analyses, individual fish relocations were assigned to a habitat class based on field observations and verified using the classification map. If field observations did not clearly state the habitat class of a relocation, the pixel value associated with the coordinates of the relocation was used.

To account for the dynamic hydrology of the Everglades landscape, a water-surface model was incorporated into the habitat classification map. Watersurface data were acquired from the Everglades Depth Estimation Network (EDEN, www.sofia.usgus.gov/eden). These data provided daily median water levels interpolated at a 400-m spatial resolution across the greater Everglades region. Since fish were relocated at weekly intervals, median water surfaces were determined for each week of the study. Weekly 400-m raster stacks were resampled to a $2 \mathrm{~m} \times 2 \mathrm{~m}$ spatial resolution to match the habitat classification raster. Ground elevation data for the study area were also obtained from EDEN through digital elevation models (DEM, https://sofia.usgs.gov/eden/models 
/groundelevmod.php). The DEM data were also resampled to a $2 \mathrm{~m} \times 2 \mathrm{~m}$ spatial resolution to match habitat classification and water surface models. The DEM was subtracted from the water surface model (see Pearlstine et al. 2007) to provide a depth estimate for each $2 \mathrm{~m} \times 2 \mathrm{~m}$ pixel across the study area. Pixels within the canal class were set to a depth of $3 \mathrm{~m}$; however, depth values associated with pixels from other classes were based on the weekly watersurface model. Pixels classified as sawgrass marsh habitat were adjusted to be $20 \mathrm{~cm}$ shallower than other marsh habitat classes (Jordan et al. 1997).

Habitat availability was defined separately for each fish relocation. Pixels were designated as available if they were within a species-specific radius centered around a relocation point. Species-specific radii were estimated using the $99^{\text {th }}$ percentile of step-lengths observed for the time scale of interest (Table 3). Weekly habitat preference was also analyzed using 100-m availability radii in order to assess how availability measures at a smaller spatial scale affect results. Since emergent landscape attributes (e.g., levees, tree islands) directly impact fish movement, binary least-cost rasters (traversable and non-traversable pixels) were generated to construct availability radii. These rasters allowed the radii to be constructed such that emergent landscape features could not be traversed by fish, which resulted in non-circular availability definitions for many relocations. The habitat classification map and associated depth data allowed for the determination of volumetric habitat proportions available to each fish at the time of relocation. Chick et al. (2004) suggests that marsh depths $>10 \mathrm{~cm}$ are suitable for fish $>8 \mathrm{~cm}$ TL in Everglades marshes; however, on the basis of observations 
from my study, I chose to treat marsh depths $<20 \mathrm{~cm}$ as too shallow for fish use. The smallest animals tagged for this study were significantly larger than the $8 \mathrm{~cm}$ threshold, justifying a greater minimum depth to avoid underestimating unavailable areas across the landscape.

Statistical Methods and Analyses

Habitat Preference

Habitat preference was analyzed by calculating population-level selection ratios for the time intervals of interest (Manly et al. 1972, Hobbs and Bowden 1982, Manly et al. 1993, Manly et al. 2002). Since individual animals were uniquely identified and habitat availability was defined for each animal based on accurately measuring habitat proportions, my study conforms to a Design III format (Thomas and Taylor 1990) with a sampling Protocol A (Manly et al. 1993, Manly et al. 2002). Selection ratios and 95\% Bonferroni adjusted confidence intervals were used to analyze habitat preference at weekly intervals and at 2hour intervals for the diel telemetry data. Selection ratios $\left(\hat{w}_{i}\right)$ for the population were calculated as

$$
\hat{\mathrm{w}}_{i}=\frac{u_{i+}}{\sum_{j=1}^{n}\left(\pi_{i j} u_{+j}\right)} \quad \text { Equation } 1
$$

where $\mathrm{u}_{i_{+}}$is the total number of relocations in habitat class $i, \pi_{i j}$ is the proportion of available habitat in class $i$ for fish $j$, and $u_{+j}$ is the number of relocations in habitat class $i$ for fish $j$. The $95 \%$ confidence interval for $\hat{w}_{i}$ was calculated as

$$
\hat{\mathrm{W}}_{i} \pm Z_{\frac{\alpha}{2 I}} \operatorname{se}\left(\hat{\mathrm{w}}_{i}\right) \quad \text { Equation } 2
$$


where $I$ is the total number of habitat classes. Selection ratios indicate preference for a habitat class if $\hat{w}_{i}>1$ and avoidance if $\hat{w}_{i}<1$. Therefore, habitat classes were deemed to be preferred if the lower confidence limits were $>1$ and avoided or used randomly if $\leq 1$ (Manly et al. 1993, Manly et al. 2002). For each habitat class, Kruskal-Wallis tests were used to determine if significant differences existed between weekly selection ratios calculated using 100-m and species-specific availability radii for each species.

For the weekly telemetry data, I used generalized linear mixed-effects models (GLMM) and multi-model selection to evaluate the effects of environmental, hydrological, and water management predictor variables on population-level selection ratios for the canal habitat class for each species. Environmental predictor variables included average daily maximum air temperature $\left({ }^{\circ} \mathrm{C}\right)$ and average daily photoperiod (hours) for the preceding 15-day period. Hydrological predictor variables included mean daily marsh depth $(\mathrm{cm})$ and change in daily marsh depth $(\mathrm{cm})$ for the preceding 15 -day period. Water management predictor variables included S-152 culvert condition (open or closed) and DPM project implementation (before or after first flow event). A random effect was incorporated into the models to estimate auto-regression at one time-step (AR1) (Cressi and Wikle 2011). A trend term was added to the model as a fixed effect to test for a linear directional change in canal selection ratios over the course of the study. Since the same fish were not always relocated each week, variation in fish size was accounted for by adding a length term that represented the average SL of all fish tracked during a weekly tracking 
session. Analyses were performed using the PROC GLIMMIX procedure (SAS 9.4, Littell et al. 2006). Models for each species used a log link function and a Poisson variance distribution. I used Akaike's Information Criterion for small sample sizes (Psuedo-AICc) to determine which models most appropriately describe the data for each species. I calculated $\Delta \mathrm{AIC}$ for each model to determine the difference in information between candidate models and the best model. Model probabilities $\left(w_{i}\right)$ were also calculated to assist with determining the best model (Anderson 2008).

\section{Movement Behavior}

Step-lengths, or the distance between two sequential relocations, were determined using Geospatial Modeling Environment (Beyer 2012). To determine rate of movement $(\mathrm{ROM})$, step-lengths were divided by the time taken to travel between locations. To determine the effect of time of day on diel movement patterns, 24-hour periods were divided into dawn, day, dusk, and night. Crepuscular periods were classified as the 2.5 -hour periods before and after sunrise and sunset, respectively. Generalized linear mixed-effects models were used to determine the effects of diel periods on ROM and if effects varied with season. Individual fish acted as the repeated measure in order to estimate autocorrelation at each time-step (Cressi and Wikle 2011). Model parameters included time of day (e.g., dawn, day, dusk, and night), season (e.g., early wet, late wet, early dry, and late dry), and interactions. I used Akaike's Information Criterion for small sample sizes (Psuedo-AICc) to determine which models best describe variation in ROM for each species. I calculated $\triangle \mathrm{AIC}_{i}$ for each model to 
determine the difference in information between candidate models and the best model. Model probabilities $\left(\mathrm{w}_{\mathrm{i}}\right)$ were also calculated to assist with determining the best model (Anderson 2008). Rate of movement estimates were also determined for weekly tracking data and ANOVAs were used to determine if ROM differed between species and season. All ROM data were $\log _{10}$ transformed to meet normality assumptions (verified with Shapiro-Wilk normality tests) and individual fish acted as replicates for ANOVA analyses. A Tukey-Kramer posteriori test was used when multiple comparisons were applicable.

\section{RESULTS}

\section{Habitat Availability}

Marsh water depths varied greatly over the course of the study, which affected availability of habitat classes (Figure 2A and 2B). Generally, seasonal patterns adhered to the expected November-April dry season and May-October wet season. The deepest marsh water depths were observed in early October 2012. During this time, the intermediate sawgrass marsh habitat class was dominant across the landscape (covered $43.5 \%$ of study area $>20 \mathrm{~cm}$ deep), followed by graminoid marsh (25.4\%), and sparse sawgrass marsh (18.1\%). All other habitat classes represented $<4 \%$ of the study area at this time. The shallowest depths observed during the study were in June 2011. At this time, graminoid marsh was the most abundant habitat class across the landscape (43.4\%), followed by sparse sawgrass marsh (25.9\%), intermediate sawgrass marsh (12.5\%), and canal (8.4\%). All other habitat classes represented $<5 \%$ of 
the landscape during this time. Large portions of WCA-3B became too shallow for fish use before substantial reductions in habitat availability occurred in the Gap (Figure 3). Habitats with higher topography, such as sawgrass marshes, became dry before graminoid marshes as water depths decreased (Figure 3 ).

\section{Habitat Use}

For the weekly telemetry data, a total of $2,902,1,688$, and 596 habitat use/availability observations were made for LMB, Bowfin, and Florida Gar, respectively. Animals from each species were observed in every habitat class over the course of the study, but not all habitat classes were used equally. During the wet season, the canal was the most frequently used habitat class for LMB and Bowfin, accounting for $59.3 \%$ and $51.5 \%$ of relocations, respectively (Figure 4). The second-most used wet-season habitat for LMB and Bowfin was sparse sawgrass marsh, representing $21.6 \%$ and $17.5 \%$ of relocations for LMB and Bowfin, respectively. The third-most used habitat by LMB and Bowfin was graminoid marsh, accounting for $10.5 \%$ and $16.7 \%$ of relocations, respectively. The sawgrass marsh class was rarely used by LMB ( $3.1 \%$ of relocations) and Bowfin (4.2\% of relocations) during the wet season, but represented the most used habitat for Florida Gar (28.1\%). The second most used class by Florida Gar was the canal ( $26.3 \%$ of relocations), followed by graminoid marsh $(16.5 \%)$, sparse sawgrass marsh (12.3\%), and cattail marsh (4.7\%).

During the dry season, the canal was the most used class by each species, representing $62.9 \%, 30.5 \%$, and $55.2 \%$ of relocations for LMB, Bowfin, 
and Florida Gar respectively (Figure 4). In the dry season, canal use increased by $6.1 \%$ for LMB, decreased by $40.8 \%$ for Bowfin, and increased by $109.9 \%$ for Florida Gar. For LMB, the second-most used habitat was sparse sawgrass marsh (12.6\% of relocations), followed by graminoid marsh (10.6\%), and sawgrass marsh (7.0\%). For Bowfin, the second-most used class was graminoid marsh ( $25.7 \%$ of relocations), followed by sparse sawgrass marsh $(24.9 \%)$, sawgrass marsh $(9.0 \%)$, and sparse graminoid marsh (6.5\%). For Florida Gar, graminoid marsh represented the second-most used dry-season habitat $(13.1 \%$ of relocations), followed by sawgrass marsh (12.6\%), sparse graminoid marsh (6.8\%), and graminoid marsh (4.2\%). Generally, Bowfin and Florida Gar demonstrated more pronounced seasonal shifts in habitat use than LMB and were more likely to be relocated in marsh habitats throughout the year (Figure 4).

Population-level selection ratios for the weekly telemetry data using species-specific habitat-availability radii indicate preference for the canal habitat class during $50.2 \%, 27.9 \%$, and $11.7 \%$ of weeks for LMB, Bowfin, and Florida Gar, respectively (Figure 2D). The sparse sawgrass marsh was the only other habitat class preferred by LMB relative to its availability ( $6.5 \%$ of weeks). Bowfin demonstrated preference for the floating broadleaf, sparse graminoid marsh, and sparse sawgrass marsh on rare occasions $(1.9 \%, 0.7 \%$, and $0.7 \%$ of weeks, respectively). No other habitat classes were used more often than expected by availability by Florida Gar during the study based on species-specific availability analyses. 
Using 100-m habitat-availability radii resulted in more habitats being used more frequently than expected by availability over the course of the weekly telemetry study. For LMB, sparse graminoid marsh, floating broadleaf, herbaceous marsh, sparse sawgrass marsh, and canal habitats were preferred $0.5 \%, 0.9 \%, 0.9 \%, 5.2 \%, 60.4 \%$ of weeks, respectively (Table 4 ). However, Kruskal-Wallis tests only detected significant increases in selection ratios for floating broadleaf, dense sawgrass marsh, and sparse sawgrass marsh (Table 5). For Bowfin, floating broadleaf, dense sawgrass marsh, graminoid marsh, and canal habitat classes were preferred in $2.2 \%, 2.2 \%, 3.0 \%$, and $57.5 \%$ of weeks, respectively (Table 4). However, Kruskal-Wallis tests only indicated a significant increase in weekly selection ratios for the floating broadleaf class (Table 5). For Florida Gar, results using 100-m radii indicate preference for cattail marsh, dense sawgrass marsh, graminoid marsh, floating broadleaf, sparse graminoid marsh, and canal classes in $1.5 \%, 1.5 \%, 1.5 \%, 3.1 \%, 6.2 \%$, and $27.7 \%$ of weeks, respectively (Table 4). For Florida Gar, Kruskal-Wallis tests indicate a significant increase in weekly selection ratios for the floating broadleaf marsh, sparse graminoid marsh, dense sawgrass marsh, sparse sawgrass marsh, and cattail marsh classes when analyses were performed using 100-m radii (Table 5).

For LMB, the model with the most support for explaining variation in canal selection ratios included the long-term trend, length, temperature, photoperiod, and DPM terms $\left(w_{i}=0.83\right.$, Table 6$)$. The second-best model $\left(w_{i}=0.16\right.$, $\left.\Delta A I C_{i}=3.30\right)$ contained the same parameters as the best model, but with the S152 term added. The probability that these two models include the best model of 
those considered is 0.99 (sum of $w_{1}(0.83)$ and $w_{2}(0.16)$ ). All other models had $\Delta \mathrm{AIC}_{i}$ values $>4$ and accounted for the remaining $1 \%$ of the Akaike weights. For the best model, coefficient estimates for the length, temperature, photoperiod, and DPM were significant at $\alpha=0.05$ (Table 7). The coefficient estimate for photoperiod was negative (less canal selectivity in the winter, which includes the dry season), but estimates for all other coefficients were positive (for example, larger LMB were more selective for the canal than smaller specimens). Notably, canal selection ratios increased after DPM implementation compared to before implementation after controlling for other parameters in the model.

For Bowfin, the model with the most support for explaining the variation in canal selection ratios included the trend, length, temperature, photoperiod, and DPM terms $\left(w_{i}=0.45\right.$, Table 6$)$. The second-best model $\left(w_{i}=0.18, \Delta A I C_{i}=1.88\right)$ contained the same parameters as the best model with the S-152 term added; however, the S-152 term did not significantly contribute to the model. All other models had $\Delta \mathrm{AIC}_{i}$ values $>2$. For the best model, coefficient estimates for the trend, length and DPM terms were significant $\alpha=0.05$, but the temperature and photoperiod terms did not significantly contribute to the model (Table 7). The coefficient estimates for the trend, length, and DPM terms were positive, suggesting that canal selection ratios increased during the study and after DPM implementation.

For Florida Gar, the variation in canal selection ratios was best explained by the model including the trend, temperature, and photoperiod terms $\left(\mathrm{w}_{\mathrm{i}}=0.66\right.$, Table 6). The length term did not significantly contribute to enhancing model fit. 
Similar to LMB and Bowfin, the second-best model contained the same terms but with the S-152 term added $\left(\mathrm{w}_{\mathrm{i}}=0.31\right)$. The DPM term could not be included in the models because all Florida Gar were tagged after DPM implementation. All other models had $\triangle \mathrm{AIC}_{i}$ values $>2$ and accounted for $3.0 \%$ of the Akaike weights. For the best model, the trend term was the only variable that significantly contributed to the model at $\alpha=0.05$ (Table 7).

For the diel telemetry data, a total of 491 and 1,174 use/availability observations were made for Florida Gar and LMB, respectively. Florida Gar were relocated in each habitat class; LMB were relocated in all classes except the sawgrass-cattail marsh class. The canal was the most used habitat class for both species ( $85.3 \%$ of Florida Gar relocations and $91.8 \%$ of LMB relocations). The second most used habitat for both species was the graminoid marsh, accounting for $3.7 \%$ and $3.1 \%$ of relocations for Florida Gar and LMB, respectively. All other habitat classes accounted for $<2 \%$ of relocations for LMB. The dense sawgrass marsh was used in $3.1 \%$ of relocations for Florida Gar, but all other classes accounted for $<3 \%$ of relocations. Diel shifts in habitat use were not detected for either species.

Population-level selection ratios for the diel telemetry data indicate preference for the canal habitat in $91.6 \%$ and $77.4 \%$ of the 2 -hour relocation intervals for LMB and Florida Gar, respectively. No other habitats were preferred by LMB; Florida Gar demonstrated preference for the dense sawgrass marsh in $3.9 \%$ of 2 -hour relocation intervals. 


\section{Movement Behavior}

Individual fish were observed moving long distances over the course of the study. Median step-lengths for weekly tracking data were $65.7 \mathrm{~m}, 78.6 \mathrm{~m}$, and $111.5 \mathrm{~m}$ for Bowfin, LMB, and Florida Gar, respectively. The longest oneweek step-length observed in the study was $14,503.8 \mathrm{~m}$ for LMB, $14,475.2 \mathrm{~m}$ for Bowfin, and 8,989.1 $\mathrm{m}$ for Florida Gar. The median step-length during diel tracking sessions was $19.0 \mathrm{~m}$ for Florida Gar and $21.8 \mathrm{~m}$ for LMB. The largest step-length observed during the diel tracking sessions was 1,554.7 $\mathrm{m}$ for Florida Gar and 1,312.0 m for LMB. Frequency distributions of weekly and diel steplengths were right-skewed for each species (Figures 5 and 6). A total of 24 LMB, 11 Bowfin, and 13 Florida Gar used degraded sections of the L67-C levee as a corridor to move from the Gap to WCA-3B. However, no individuals were observed traversing the degraded levee corridors during the diel tracking sessions.

For LMB, the model that best explained diel variation in ROM included season, time of day, and season ${ }^{\star}$ time of day terms $\left(w_{i}=0.98\right.$, Table 8$)$. All other models had $\triangle \mathrm{AIC}_{i}$ values $>7$ and accounted for $3.0 \%$ of the Akaike weights. For the best model, the season and time-of-day terms contributed significantly to the model at $\alpha=0.05$ (Table 9). Parameter estimates indicate that ROM were highest late in the wet season and LMB tended to be least active at dusk and most active at dawn. Similarly, for Florida Gar, variation in diel ROM was best explained by the model including season, time of day, and season*time of day terms $\left(w_{i}=0.99\right.$, Table 8). All other models had $\Delta \mathrm{AIC}_{i}$ values $>12$ and accounted for $0.25 \%$ of the 
Akaike weights. For the best model, only the time of day term contributed significantly to the model at $\alpha=0.05$ (Table 9). Parameter estimates indicate that Florida Gar were least active during the day and most active at dusk.

When weekly telemetry data were pooled (i.e., not separated by season) there were no significant differences in ROM between species $\left(F_{2,233}=1.085\right.$, $p=0.34$, Figure 7). There was no significant effect of season on ROM for Gar or Bowfin, however, ROM was $17.5 \%$ higher in the dry season for LMB $\left(F_{1,209}=10.152, p=0.002\right)$. There was an interaction between season and species for Bowfin, which had a $20.1 \%$ lower ROM in the dry season than Florida Gar $\left(F_{2,193}=3.416, p=0.035\right)$ and LMB had a $16.4 \%$ lower wet season ROM than Bowfin and Florida $\operatorname{Gar}\left(F_{2,189}=3.89, p=0.036\right)$.

\section{DISCUSSION}

The results from this study highlight the importance of canals as deepwater refuges for large-bodied fishes in the freshwater Everglades, even when water depths are sufficient for dispersal into the surrounding marsh. The canal was the most frequently used dry-season habitat class by all three species but represents only a small proportion of the submerged landscape even in unusually dry periods. Selection ratios indicate preference for the canal habitat class by all three species while other classes (including sparse sawgrass marsh, dense sawgrass marsh, floating broadleaf, and sparse graminoid marsh) were preferred only rarely and to varying degrees among species when using species-specific availability measures. For each species, variability in canal selection ratios was 
affected by water management and environmental factors rather than hydrological factors. Most notably, canal selection ratios increased after DPM implementation for LMB and Bowfin. The diel study did not detect significant crepuscular or nocturnal shifts in habitat use for LMB or Florida Gar, so it is likely that the weekly telemetry data adequately describe the habitat use-availability patterns for these species.

Previous studies of large-bodied fish movements in the Everglades support the existence of a strong relationship between habitat use and fluctuating hydrology. For instance, LMB, Bowfin and Mayan cichlids Cichlasoma urophthalmus demonstrate a higher probability of marsh occupancy with increasing water depths (Parkos and Trexler 2014, Bush 2017). For LMB and Bowfin, the distance of relocations from a canal is influenced by variation in hydrology more than environmental cues, including photoperiod and temperature (Bush 2017). For this reason, the variability of canal selection ratios was expected to have been best explained by models including hydrological predictor variables. However, these predictor variables were not included in the best models for any of the species in this study. This is likely the result of selection ratio calculations, which are heavily influenced by the proportions of available habitat classes within the availability radii centered around a relocation point. The canal makes up only a small proportion of the submerged landscape even in the driest conditions, which may lead to inflation of the selection ratio calculations and obscure the impact of dynamic hydrology on their variability. 
The abundance of large fishes in deep-water refuges, including alligator holes and canals, has been shown to increase during the dry season across different regions of the Everglades (Kushlan 1974, Rehage and Trexler 2006, Parkos et al. 2011, Hijuelos 2012, Bush 2017). This seasonal influx of fishes into refuge habitats can result in significant changes in community structure (Rehage and Loftus 2007, Parkos et al. 2011). The movement of large fishes from ephemeral marshes to deep-water habitats corresponds with increased prey densities in these areas, including small-bodied fishes and macroinvertebrates (Rehage and Trexler 2006), which may result in increased prey encounter rates relative to marsh habitats (Turesson and Brönmark 2007). Canal margins represent a transitional area between heavily vegetated marshes with high stem density to a relatively open littoral zone and may contribute to increased predation success for the study species (Savino and Stein 1982). Predators of these large-bodied fishes, such as the river otter Lutra canadensis and American alligator Alligator mississippiensis, may also demonstrate similar shifts in habitat use (Humphrey and Zinn 1982, Kushlan 1974), which may result in increased predation pressure on the study species. Seasonal shifts from marsh habitats to deep-water refuges may represent a trade-off between reducing the threat of desiccation, increasing prey encounter rates and capture success, risking exposure to predators, and elevated interspecific and intraspecific competition.

Although restoration efforts are progressing, the regional hydrology of the Everglades remains heavily managed and these practices have profound implications for the ecology of the system (Sklar et al. 2005). Results from my 
study indicate that water management efforts, including DPM implementation and water releases from the S-152 culverts, impact the habitat use of large-bodied fishes. Selection ratios for the canal increased significantly after DPM implementation for LMB and Bowfin. The direct cause of this increase is uncertain; however, it may have been induced by the canal backfilling treatments associated with the DPM project. Removing a large portion of the L67-C levee and backfilling the adjacent canal enhanced the structural complexity of $>7,300$ $\mathrm{m}^{2}$ of canal and created a substantial area similar to the canal margin in terms of vegetation, substrate, and depth. The development of high quality habitat and an increase in prey fish density within the canal backfill area (Bush 2017) may have led to an increase in canal selection ratios. Additionally, the removal of segments of the L67-C levee created corridors for fish movement from the Gap to WCA-3B that were used by $17 \%, 11 \%$, and $32 \%$ of tagged LMB, Bowfin, and Florida Gar, respectively.

The canal represented the most commonly preferred habitat class for each species, however, there were slight differences in habitat use among species. For instance, LMB showed less pronounced shifts in canal use between seasons than Florida Gar and Bowfin (Figure 4). Florida Gar were more likely to be relocated in the sawgrass marsh than any other species. Generally, Bowfin and Florida Gar appeared to rely more heavily on marsh habitats than LMB. Bowfin demonstrated preference for more habitat classes than LMB and Florida Gar based on species-specific analyses, suggesting that they may be more willing to move into the marsh and away from the relative safety of the canal. 
Another radio-telemetry study in this area found that Bowfin had a $20 \%$ higher probability of marsh occupancy than LMB under the same environmental conditions (Bush 2017). Marsh habitats generally have high structural complexity and may exhibit diel shifts in dissolved oxygen concentrations (McCormick and Laing 2003). Bowfin and Florida Gar have adaptations that may allow them to thrive in these harsh conditions, such as tough imbricated scales and highly vascularized airbladders.

This study focused on habitat use and movement patterns at the population level, but individual variation in movement strategies was evident for each species. For instance, Florida Gar LP03 and Florida Gar LP08 remained within $2 \mathrm{~km}$ of each other while radio-tracked from November 2015 to September 2016. During this period, LP03 was relocated almost exclusively in sparseintermediate sawgrass marshes while LP08 remained in the canal or in graminoid marshes in close proximity to the canal margin (Figure 8A). The median ROM for LP03 and LP05 were 17.9 m/day and 8.6 m/day, respectively. In contrast, Florida Gar LP16 had movements that spanned a much larger geographic range. LP16 traveled between the Gap and WCA-3B regularly and used the north degraded levee corridor five times while radio-tracked from January 2016-August 2016 (Figure 8B). This fish was observed using every habitat excluding the sawgrass/cattail marsh class and had a substantially higher median ROM of $71.6 \mathrm{~m} /$ day.

Since measures of habitat availability play a critical role in calculating selectivity indices, observing differences between analyses using 100-m and 
species-specific radii was expected. For each species, using the 100-m availability radii resulted in preference for more marsh habitat classes. This is particularly true for Florida Gar, which demonstrated preference for only the canal class when analyses were based on the larger species-specific radii, but demonstrated preference for five marsh classes in addition to the canal when analyses were based on relatively small $100-\mathrm{m}$ radii. Selection ratio calculations are greatly influenced by the proportions of each habitat available to an individual fish at the time of relocation. For this reason, tagged animals residing in the marsh and away from the influence of the canal may cause inflation of marshclass selection ratios at the population level. Similarly, if individual fish are located in the canal, using a smaller availability radius will result in the canal maintaining a higher proportion of the volumetric habitat available to the animal, which will lower population-level selection ratios for the canal class. The 100-m radius designation was approximately the median weekly step-length for each species. Since about half of the observed steps were within the smaller radius, these data may provide insight into short-distance movements. However, the $100-\mathrm{m}$ radius is an under-estimation of availability since fish of each species have been observed making long-distance movements. We currently have no information on how these fish gain information about habitat options in their environment as a basis for habitat choice or why relatively long-distance movements are common. However, analyses at both scales indicated habitat use was non-random and changed with seasonal conditions. 
The canal network in southeast Florida supports a flourishing recreational fishing industry. LMB represent the most targeted native fish by recreational anglers in the freshwater Everglades and support a total economic output of $\$ 141$ million (Fedler 2009). The network of canals that traverses the landscape, particularly surrounding the Water Conservation Areas, allows fishers to access areas of the Everglades that would be otherwise too heavily vegetated and shallow for standard motorboats. A series of "boat trails" has been constructed by the Florida Fish and Wildlife Conservation Commission (FWC) and SFWMD to allow fishers to access marsh habitats in WCA-3A adjacent to the L67-A canal; however, canal fishing remains the predominate focus of recreational fishers. Complete canal backfilling is crucial to restoring historical flow regimes in the Everglades but is likely to disrupt an economically valuable industry. Partial backfilling may provide a deep-water refuge for large fishes, preserve canal access for fishers, and allow for more natural flow regimes.

The results from this study reiterate the importance of canals as an anthropogenic deep-water refuge for large-bodied fishes in the Florida Everglades. More importantly, this study highlights the impact of restorationdriven landscape alteration on animal-habitat relationships in a dynamic aquatic ecosystem. Results indicate a significant increase in canal selection ratios for LMB and Bowfin after DPM implementation. All three study species demonstrated preference for the L67-C canal even though this habitat only represents a minor proportion of the submerged landscape. The canal and levee network that began construction in the late 1880 s poses a substantial challenge 
for the monumental Everglades restoration efforts that began in 2000. Canal backfilling is critical for restoring historical hydrological regimes across the Everglades landscape. Levee removal and partial canal backfilling may present a viable solution for reestablishing sheetflow across the region, providing suitable dry-season refuge for aquatic organisms, and maintaining the Everglades' reputation as a world-class freshwater fishery. 


\section{REFERENCES}

Anderson DR. 2008. Model based inference in the life sciences: a primer on evidence. Springer Science. New York.

Batzer DP, Wissinger SA. 1996. Ecology of insect communities in nontidal wetlands. Annual Review of Entomology 41:75-100.

Beyer HL. 2012. Geospatial modelling environment. Version 0.7.4. Available via www.spatialecology.com/gme/gmedownload.htm

Beyer HL, Haydon DT, Morales JM, Frair JL, Hebblewhite M, Mitchell M, Matthiopoulos J. 2010. The interpretation of habitat preference metrics under use-availability designs. Philosophical Transactions of the Royal Society B 365:2245-2254.

Bush MR. 2017. Experimental analysis of the effects of hydroscape structure on fishes in a dynamic wetland. Ph.D. Dissertation. Florida International University, Miami, Florida.

Braaten PJ, Elliott CM, Rhoten JC, Fuller DB, McElroy BJ. 2015. Migrations and swimming capabilities of endangered pallid sturgeon (Scaphirhynchus albus) to guide passage designs in the fragmented Yellowstone River. Restoration Ecology 23:186-195.

Chick JH, Coyne S, Trexler JC. 1999. Effectiveness of airboat electrofishing for sampling fishes in shallow, vegetated habitats. North American Journal of Fisheries Management 19:957-967.

Chick JH, Ruetz CR, Trexler JC. 2004. Spatial scale and abundance patterns of large fish communities in freshwater marshes of the Florida Everglades. Wetlands 24:652-664.

Cressie N, Wikle CK. 2011. Statistics for spatio-temporal data. John Wiley \& Sons. Hoboken, New Jersey.

DeAngelis DL. 1994. Synthesis: spatial and temporal characteristics of the environment. Pages 307-320. In: Everglades: The Ecosystem and Its Restoration. SM Davis and JC Ogden (eds). St. Lucie Press. Boca Raton, Florida.

Fedler A. 2009. The economic impact of recreational fishing in the Everglades region. Report to the Everglades Foundation. https://www.bonefish tarpontrust.org/downloads/research-reports/stories/evergladeseconomics-report.pdf 
Gibbs JP. 2000. Wetland loss and biodiversity conservation. Conservation Biology 14:314-317.

Gunderson L. 1994. Vegetation of the Everglades: determinants of community composition. Pages 323-340. In: Everglades: The Ecosystem and Its Restoration. SM Davis and JC Ogden (eds). St. Lucie Press. Boca Raton, Florida.

Hijuelos AC. 2012. Spatial and temporal patterns in the distribution, behavior, and activity of fishes in canals of the Everglades. Master's Thesis. Florida International University, Miami, Florida.

Hobbs NT, Bowden DC. 1982. Confidence intervals on food preference indices. Journal of Wildlife Management 46:505-507.

Humphrey SR, Zinn TL. 1982. Seasonal habitat use by river otters and Everglades mink in Florida. The Journal of Wildlife Management 46:375381.

Johnson CA. 1994. Cumulative impacts to wetlands. Wetlands 14:49-55.

Jordan F, Jelks HL, Kitchens WM. 1997. Habitat structure and plant community composition in northern Everglades wetland landscape. Wetlands 17:275283.

Kerezsy A, Balcombe SR, Tischler M, Arthington AH. 2013. Fish movement strategies in an ephemeral river in the Simpson Desert, Australia. Austral Ecology 30:798-808

Kushlan JA. 1974. Observations on the role of the American alligator (Alligator mississippiensis) in the southern Florida wetlands. Copeia 1974:993-996.

Kwak TJ. 1998. Lateral movement and use of floodplain habitat by fishes of the Kankakee River, Illinois. American Midland Naturalist 120:241-249.

Larsen L, Aumen N, Bernhardt C, Engel V, Hagerthey S, Harvey J, Leonard L, McCormick P, McVoy C, Noe G, Nungesser M, Rutchey K, Sklar F, Troxler T, Volin J, Willard D. 2011. Recent and historic drivers of landscape change in the Everglades ridge, slough, and tree island mosaic. Critical Reviews in Environmental Science and Technology 41:344-381.

Light SS, Dineen JW. 2004. Water control in the Everglades: a historical perspective. Pages 47-83. In: Everglades: The Ecosystem and Its 
Restoration. SM Davis and JC Ogden (eds). St. Lucie Press. Boca Raton, Florida.

Littell RC, Milliken GA, Stoup WW, Wofinger RD, Schabenberger O. 2006. SAS for mixed models. Second Edition. SAS Institute. Cary, North Carolina.

Manly BFJ, McDonald LL, Thomas DL, McDonald TL. 1993. Resource selection by animals: statistical design and analysis for field studies. Chapman \& Hall. London, England.

Manly BFJ, McDonald LL, Thomas DL, McDonald TL, Erickson WP. 2002. Resource selection by animals: statistical design and analysis for field studies. Second Edition. Kluwer Academic Publishers. Boston, Massachusetts.

Manly BFJ, Miller P, Cook LM. 1972. Analysis of a selective predation experiment. American Naturalist 106:719-736.

McCormick PV, Laing JA. 2003. Effects of increased phosphorous loading on dissolved oxygen in a subtropical wetland, the Florida Everglades. Wetlands Ecology and Management 11:199-2016.

McVoy C, Park Said W, Obeysekera J, VanArman J, Dreschel T. 2011. Landscapes and hydrology of the predrainage Everglades. University Press of Florida. Gainesville, Florida.

Mulcahy DM. 2003. Surgical implantation of transmitters into fish. ILAR Journal 44:295-306.

NRC. 2012. Progress toward restoring the Everglades: the fourth biennial review. National Academies Press.

Pearlstine L, Higer A, Palaseanu M, Fujisaki I, Mazzotti F. 2007. Spatially continuous interpolation of water stage and water depths using the Everglades Depth Estimation Network (EDEN). Institute of Food and Agriculture, University of Florida. Gainesville, Florida. CIR1521.

Parkos JJ, Ruetz CR, Trexler JC. 2011. Disturbance regime and limits on benefits of refuge use for fishes in a fluctuating hydroscape. Oikos 120:1519-1530.

Parkos JJ, Trexler JC. 2014. Origins of functional connectivity in a humanmodified wetland landscape. Canadian Journal of Fisheries and Aquatic Sciences 1429:1418-1429. 
Pépino M, Rodríguez MA, Magnan P. 2012. Fish dispersal in fragmented landscapes: a modeling framework for quantifying the permeability of structural barriers. Ecological Applications 22:1435-1445.

Rayner TS, Pusey BJ, Pearson RG. 2008. Seasonal flooding, instream habitat structure and fish assemblages in the Mulgrave River, north-east Queensland: towards a new conceptual framework for understanding fishhabitat dynamics in small tropical rivers. Marine and Freshwater Research 59:97-116.

Rehage JS, Trexler JC. 2006. Assessing the net effect of anthropogenic disturbance on aquatic communities in wetlands: community structure relative to distance from canals. Hydrobiologia 569:359-373.

Rehage JS, Loftus WF. 2007. Seasonal fish community variation in headwater mangrove creeks in the southwestern Everglades: an examination of their role as dry-down refuges. Bulletin of Marine Science 80:625-645.

Roe JH, Kingsbury BA, Herbert NR. 2004. Comparative water snake ecology: conservation of mobile animals that use temporally dynamic resources. Biological Conservation 118:79-89.

Ruetz CR, Trexler JC, Jordan F, Loftus WF, Perry SA. 2005. Population dynamics of wetland fishes: spatio-temporal patterns synchronized by hydrological disturbance? Journal of Animal Ecology 74:322-332.

Savino JF, Stein RA. 1982. Predator-prey interaction between largemouth bass and bluegills as influenced by simulated, submersed vegetation. Transactions of the American Fisheries Society 111:255-266.

SFWMD. 2010. Managing and protecting water in South Florida. https://www.sfwmd.gov/sites/default/files/documents/spl_managing_sf.pdf

Sklar FH, Chimney MJ, Newman S, McCormick P, Gawlik D, Miao S, McVoy C, Said W, Newman J, Coronado C, Crozier G, Korvela M, Rutchey K. 2005. The ecological-societal underpinnings of Everglades restoration. Frontiers in Ecology and the Environment 3:161-169.

Thomas DL, Taylor EJ. 1990. Study designs and tests for comparing resource use and availability. The Journal of Wildlife Management 54:322-330.

Turesson H, Brönmark C. 2007. Predator-prey encounter rates in freshwater piscivores: effects of prey density and water transparency. Oecologia 153:281-290. 
Ulrich D. 2005. A review on habitats, plant traits and vegetation of ephemeral wetlands: a global perspective. Phytocoenologia 35:533-706.

USACE and SFWMD. 1999. Central and southern Florida comprehensive review study: final integrated feasibility report and programmatic implementation statement. http://141.232.10.32/pub/restudy_eis.aspx.

Winemiller KO, Jepsen DB. 1998. Effects of seasonality and fish movement on tropical river food webs. Journal of Fish Biology 53:267-296.

Winter JD. 1983. Underwater biotelemetry. Pages 371-396. In: Fisheries Techniques. Nielson LA, Johnson JD (eds). American Fisheries Society. Bathesda, Maryland. 
Table 1. Mean number of relocations and days at large for each species over the course of the weekly telemetry study.

\begin{tabular}{lcc}
\hline Species & Relocations & Days at Large \\
\hline LMB & $21.7(2-29)$ & $175.1(21-383)$ \\
Bowfin & $18.0(2-29)$ & $149.2(13-350)$ \\
Florida Gar & $24.6(8-46)$ & $244.6(152-374)$ \\
\hline
\end{tabular}


Table 2. Number of individuals of $L M B$ and Florida Gar radio-tracked during each 24-hour tracking session from June 2016 through April 2017.

\begin{tabular}{cccc}
\hline Session & Dates & Number of LMB & Number of Florida Gar \\
\hline 1 & June 7-June 8 2016 & 7 & 4 \\
2 & June 14-June 15 2016 & 6 & 3 \\
3 & June 21-June 22 2016 & 6 & 4 \\
4 & Oct. 13-Oct. 14 2016 & 6 & 4 \\
5 & Oct. 20-Oct. 21 2016 & 6 & 3 \\
6 & Oct. 27-Oct. 28 2016 & 7 & 2 \\
7 & Nov. 3-Nov. 4 2016 & 9 & 4 \\
8 & Jan. 12-Jan. 13 2017 & 10 & 2 \\
9 & Jan. 19-Jan. 20 2017 & 9 & 4 \\
10 & Jan. 26-Jan. 27 2017 & 8 & 4 \\
11 & Mar. 30-Mar. 31 2017 & 9 & 3 \\
12 & Apr. 6-Apr. 7 2017 & 8 & 3 \\
13 & Apr. 13-Apr. 14 2017 & 9 & 3 \\
\hline
\end{tabular}


Table 3. Distance of availability radii used to determine habitat proportions for each species for habitat use analyses.

\begin{tabular}{lcc}
\hline Species & Weekly Radii $(\mathrm{m})$ & Diel Radii $(\mathrm{m})$ \\
\hline LMB & $5,995.0$ & 538.6 \\
Bowfin & $7,149.4$ & - \\
Florida Gar & $6,567.5$ & 627.5 \\
\hline
\end{tabular}


Table 4. Percent of weeks each habitat class was preferred based on 100-m and species-specific availability selection ratio calculations.

\begin{tabular}{rcccccc}
\hline & \multicolumn{2}{c}{ LMB } & \multicolumn{2}{c}{ Bowfin } & \multicolumn{2}{c}{ Florida Gar } \\
& $100 \mathrm{~m}$ & Species-Specific & $100 \mathrm{~m}$ & Species-Specific & $100 \mathrm{~m}$ & Species-Specific \\
\hline Floating Broadleaf & $0.9 \%$ & 0 & $2.2 \%$ & $1.9 \%$ & $3.1 \%$ & 0 \\
Graminoid Marsh & 0 & 0 & $3.0 \%$ & 0 & $1.5 \%$ & 0 \\
Sparse Graminoid Marsh & $0.5 \%$ & $0.4 \%$ & 0 & $0.6 \%$ & $6.2 \%$ & 0 \\
Sawgrass Marsh & 0 & 0 & 0 & 0 & 0 & 0 \\
Dense Sawgrass Marsh & $0.9 \%$ & 0 & $2.2 \%$ & 0 & $1.5 \%$ & 0 \\
Sparse Sawgrass Marsh & $5.2 \%$ & $6.5 \%$ & 0 & $0.6 \%$ & 0 & 0 \\
Sawgrass/Cattail Marsh & 0 & 0 & 0 & 0 & 0 & 0 \\
Cattail Marsh & 0 & 0 & 0 & 0 & $1.5 \%$ & 0 \\
Herbaceous Marsh & $0.9 \%$ & 0 & 0 & 0 & 0 & 0 \\
Canal & $60.4 \%$ & $50.2 \%$ & $57.5 \%$ & $27.9 \%$ & $27.7 \%$ & $26.5 \%$ \\
\hline
\end{tabular}


Table 5. Results of Kruskal-Wallis tests used to determine if significant differences exist between selection ratio calculations using 100-m and species-specific availability radii.

\begin{tabular}{|c|c|c|c|c|c|c|c|c|c|}
\hline & \multicolumn{3}{|c|}{ LMB } & \multicolumn{3}{|c|}{ Bowfin } & \multicolumn{3}{|c|}{ Florida Gar } \\
\hline & \multicolumn{3}{|l|}{ Kruskal-Wallis } & \multicolumn{3}{|l|}{ Kruskal-Wallis } & \multicolumn{3}{|l|}{ Kruskal-Wallis } \\
\hline & Chi-Square & $\mathrm{df}$ & P-value & Chi-Square & df & P-value & Chi-Square & $\mathrm{df}$ & P-value \\
\hline Floating Broadleaf & 37.3 & 18 & 0.005 & 55.5 & 15 & 0.000 & 45.1 & 12 & 0.000 \\
\hline Graminoid Marsh & - & - & - & 111.3 & 108 & 0.395 & 41.1 & 44 & 0.598 \\
\hline Sparse Graminoid Marsh & 42.5 & 41 & 0.405 & 54.8 & 58 & 0.593 & 38.5 & 23 & 0.023 \\
\hline Sawgrass Marsh & - & - & - & - & - & - & - & - & - \\
\hline Dense Sawgrass Marsh & 80.1 & 46 & 0.001 & 34.7 & 28 & 0.179 & 24.3 & 9 & 0.004 \\
\hline Sparse Sawgrass Marsh & 195.9 & 136 & 0.001 & 104.2 & 108 & 0.586 & - & - & - \\
\hline Sawgrass/Cattail Marsh & - & - & - & - & - & - & - & - & - \\
\hline Cattail Marsh & - & - & - & - & - & - & 33.9 & 14 & 0.002 \\
\hline Herbaceous Marsh & 16.7 & 11 & 0.118 & - & - & - & - & - & - \\
\hline Canal & 217.1 & 214 & 0.427 & 124.9 & 124 & 0.461 & 62.7 & 57 & 0.281 \\
\hline
\end{tabular}




\section{Table 6. Results of generalized linear mixed-effects models of factors affecting canal selection ratios for LMB, Bowfin, and Florida Gar.}

\begin{tabular}{|c|c|c|c|c|}
\hline Model & -2 Log Psuedo Likelihood & Psuedo-AICc & $\triangle \mathrm{AICc}$ & $\mathrm{w}_{\mathrm{i}}$ \\
\hline \multicolumn{5}{|l|}{ LMB } \\
\hline Trend + Length + Temp + Photo + DPM & 400.55 & 404.60 & - & 0.83087 \\
\hline Trend + Length + Temp + Photo + DPM + S-152 & 403.84 & 407.90 & 3.30 & 0.15957 \\
\hline Trend + Length + Temp + Photo + DPM + Mean Depth & 409.86 & 413.91 & 9.31 & 0.00790 \\
\hline Trend + Length + Temp + Photo + DPM + S-152 + Mean Depth & 413.02 & 417.08 & 12.48 & 0.00162 \\
\hline Trend + Length + Temp + Photo + DPM + S-152 + Mean Depth $+\Delta$ Depth & 420.78 & 424.83 & 20.23 & 0.00003 \\
\hline Length + Temp + Photo & 431.68 & 435.74 & 31.14 & 0.00000 \\
\hline Trend + Length + Temp + Photo & 442.11 & 446.16 & 41.56 & 0.00000 \\
\hline \multicolumn{5}{|l|}{$\begin{array}{rr} & \text { Bowfin } \\
\end{array}$} \\
\hline Trend + Length + Temp + Photo + DPM & 380.23 & 384.31 & - & 0.44786 \\
\hline Trend + Length + Temp + Photo + DPM + S-152 & 382.10 & 386.19 & 1.88 & 0.17494 \\
\hline Length + Temp + Photo & 382.53 & 386.61 & 2.30 & 0.14181 \\
\hline Trend + Length + Temp + Photo + DPM + Mean Depth & 382.54 & 386.62 & 2.31 & 0.14110 \\
\hline Trend + Length + Temp + Photo + DPM + S-152 + Mean Depth & 383.55 & 387.63 & 3.32 & 0.08515 \\
\hline Trend + Length + Temp + Photo + DPM + S-152 + Mean Depth $+\Delta$ Depth & 388.89 & 392.98 & 8.67 & 0.00587 \\
\hline Trend + Length + Temp + Photo & 390.07 & 394.15 & 9.84 & 0.00327 \\
\hline \multicolumn{5}{|l|}{ Florida Gar } \\
\hline Trend + Temp + Photo & 133.91 & 138.11 & - & 0.663954 \\
\hline Trend + Temp + Photo + S-152 & 135.46 & 139.66 & 1.55 & 0.305886 \\
\hline Trend + Temp + Photo + S-152 + $\Delta$ Depth & 140.93 & 145.14 & 7.03 & 0.019751 \\
\hline Trend + Temp + Photo + Mean Depth & 142.34 & 146.55 & 8.44 & 0.009759 \\
\hline Trend + Temp + Photo + S-152 $+\Delta$ Depth + Mean Depth & 147.76 & 151.97 & 13.86 & 0.000649 \\
\hline
\end{tabular}


Table 7. Effects of environmental, hydrological, and water management predictor variables on the variability of canal selection ratios for each species. Only models with $\triangle A I C c$ values $<2$ are shown.

\begin{tabular}{|c|c|c|c|c|}
\hline & Estimate $\pm \mathrm{SE}$ & $\begin{array}{l}\text { Kenward- } \\
\text { Rogers df }\end{array}$ & F-value & $P$-value \\
\hline \multicolumn{5}{|c|}{$\begin{array}{c}\text { LMB } \\
\text { Model: } \text { Trend + Length + Temp + Photo + DPM }\end{array}$} \\
\hline Trend & $0.0008 \pm 0.00$ & $1,222.5$ & 0.85 & 0.3579 \\
\hline Length & $0.1671 \pm 0.03$ & $1,221.5$ & 37.26 & $<0.0001$ \\
\hline Temp & $0.0648 \pm 0.02$ & $1,208.7$ & 13.84 & 0.0003 \\
\hline Photo & $-0.1751 \pm 0.05$ & $1,201.0$ & 13.85 & 0.0003 \\
\hline DPM & $0.8667 \pm 0.12$ & 1, 222.8 & 54.63 & $<0.0001$ \\
\hline \multicolumn{5}{|c|}{$\begin{array}{c}\text { Bowfin } \\
\text { Model: } \text { Trend + Length }+ \text { Temp }+ \text { Photo + DPM }\end{array}$} \\
\hline Trend & $0.0067 \pm 0.00$ & $1,144.0$ & 7.37 & 0.0074 \\
\hline Length & $0.1093 \pm 0.04$ & $1,143.4$ & 7.92 & 0.0056 \\
\hline Temp & $-0.0307 \pm 0.03$ & $1,143.6$ & 0.85 & 0.3568 \\
\hline Photo & $-0.0943 \pm 0.10$ & $1,137.4$ & 0.97 & 0.3262 \\
\hline DPM & $0.9291 \pm 0.17$ & $1,134.5$ & 28.38 & $<.0001$ \\
\hline \multicolumn{5}{|c|}{ Model: Trend + Length + Temp + Photo + DPM + S-152 } \\
\hline$\overline{T r e n d}$ & $0.0068 \pm 0.00$ & $1,142.9$ & 7.51 & 0.0069 \\
\hline Length & $0.1062 \pm 0.04$ & $1,141.8$ & 7.32 & 0.0077 \\
\hline Temp & $-0.0269 \pm 0.03$ & $1,144.5$ & 0.63 & 0.4297 \\
\hline Photo & $-0.1211 \pm 0.11$ & $1,144.7$ & 1.23 & 0.2684 \\
\hline DPM & $0.9508 \pm 0.18$ & $1,135.6$ & 28.17 & $<.0001$ \\
\hline S-152 & $0.0926 \pm 0.18$ & $1,124.5$ & 0.26 & 0.6108 \\
\hline \multicolumn{5}{|c|}{$\begin{array}{c}\text { Florida Gar } \\
\text { Model: Trend + Temp + Photo }\end{array}$} \\
\hline Trend & $-0.0114 \pm 0.00$ & $1,62.39$ & -3.41 & 0.0011 \\
\hline Temp & $-0.0174 \pm 0.04$ & $1,41.69$ & -0.44 & 0.6601 \\
\hline Photo & $-0.2020 \pm 0.10$ & $1,62.86$ & -1.95 & 0.0559 \\
\hline \multicolumn{5}{|c|}{ Model: Trend + Temp + Photo + S-152 } \\
\hline Trend & $-0.0106 \pm 0.00$ & $1,61.53$ & 9.14 & 0.0036 \\
\hline Temp & $-0.0270 \pm 0.04$ & $1,39.44$ & 0.4 & 0.5308 \\
\hline Photo & $-0.1452 \pm 0.13$ & $1,61.92$ & 1.26 & 0.2664 \\
\hline S-152 & $-0.1415 \pm 0.19$ & $1,61.11$ & 0.58 & 0.4477 \\
\hline
\end{tabular}


Table 8. Results of generalized linear mixed-effects models of factors affecting diel ROM for LMB and Florida Gar.

\begin{tabular}{|c|c|c|c|c|}
\hline Model & \multicolumn{3}{|c|}{-2 Log Psuedo Likelihood Psuedo-AICc $\Delta$ AICc } & $\mathrm{w}_{\mathrm{i}}$ \\
\hline \multicolumn{5}{|l|}{ LMB } \\
\hline Season + Time of Day + Season*Time of Day & 3606.5 & 3610.5 & - & 0.9811 \\
\hline Season + Time of Day & 3614.4 & 3618.4 & 7.90 & 0.0189 \\
\hline \multicolumn{5}{|l|}{ Florida Gar } \\
\hline Season + Time of Day + Season*Time of Day & 1432.6 & 1436.7 & - & 0.9996 \\
\hline Season + Time of Day & 1448.3 & 1452.3 & 15.60 & 0.0004 \\
\hline
\end{tabular}


Table 9. Significance of season and time of day on ROM for LMB and Florida Gar for generalized linear mixed-effects models. Results are only given for models with lowest Pseudo-AICc scores.

\begin{tabular}{|c|c|c|c|}
\hline & $\begin{array}{l}\text { Kenward- } \\
\text { Rogers df }\end{array}$ & F-value & P-value \\
\hline \multicolumn{4}{|l|}{ 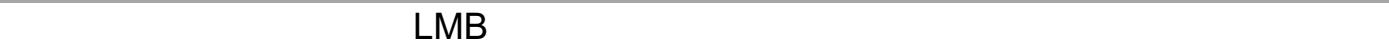 } \\
\hline Season & 3,197 & 7.18 & 0.0001 \\
\hline Time of Day & 3,1006 & 3.02 & 0.0288 \\
\hline Season*Time of Day & 9,1027 & 1.42 & 0.1750 \\
\hline \multicolumn{4}{|c|}{$\begin{array}{c}\text { Florida Gar } \\
\text { Model: Season + Time of Day + Season*Time of Day }\end{array}$} \\
\hline Season & 3,112 & 2.15 & 0.0977 \\
\hline Time of Day & 3,320 & 10.38 & $<.0001$ \\
\hline Season*Time of Day & 9,390 & 1.67 & 0.0943 \\
\hline
\end{tabular}




\section{FIGURE CAPTIONS}

Figure 1. A) Map of South Florida demonstrating the geographic location of the study area; B) Map of DPM study area with water management features and spatial arrangement of habitat classes. Spatial resolution of pixels is $2 \mathrm{~m}$.

Figure 2. A) Hydrograph of daily median water depth for representative graminoid marshes in the Gap and WCA-3B; B) Mean proportion of available habitat that was in the canal class for tagged fish population reported separately by species; C) Proportion of tagged fish in canal habitat reported separately by species. D) Population-level selection ratio for canal habitat versus time reported separately by species.

Figure 3. Representative time-series of habitat classification maps for a portion of the study area demonstrating intra-annual change in habitat availability from November 2014 to October 2015. Spatial resolution of pixels is 2 $\mathrm{m}$.

Figure 4. Bar chart illustrating percent of radio-telemetry relocations in most used habitat classes reported separately by season.

Figure 5. Step-length frequency distributions for weekly telemetry data.

Figure 6. Step-length frequency distributions for diel telemetry data.

Figure 7. Rate of movement (ROM) for LMB, Bowfin, and Florida Gar based on weekly tracking data. An * indicates a significant $(p<0.05)$ intraspecific difference in ROM between seasons. For each season, bars with a letter in common are not significantly different. Error bars indicate $95 \%$ confidence intervals.

Figure 8. A) Map demonstrating movement patterns of LP03 and LP08 from November 2015-September 2016. Movements for both fish were confined to relatively small ranges. LP03 resided primarily in marsh habitats while LP08 resided within the canal or in adjacent marshes; B) Map demonstrating movements of LP16 from January 2016-August 2016. LP16 used all habitats except the sawgrass-cattail marsh class. Lines between sequential location points indicate Euclidean path. 


\section{Figure 1}

A)

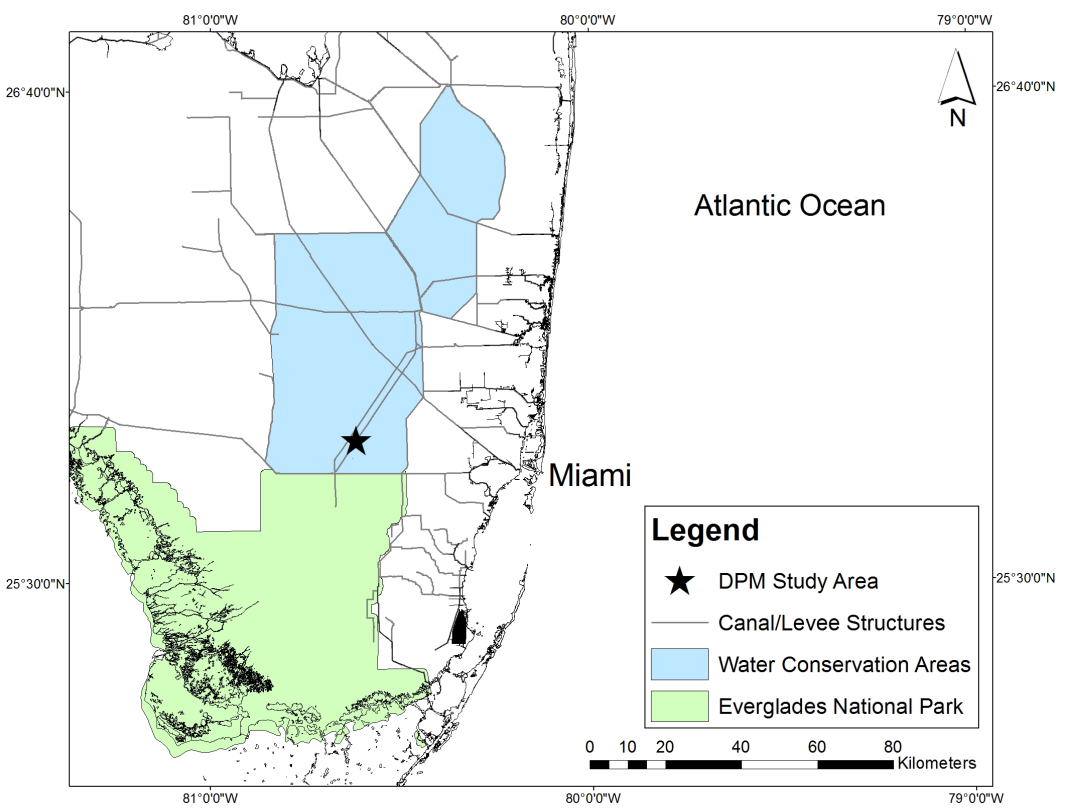

B)

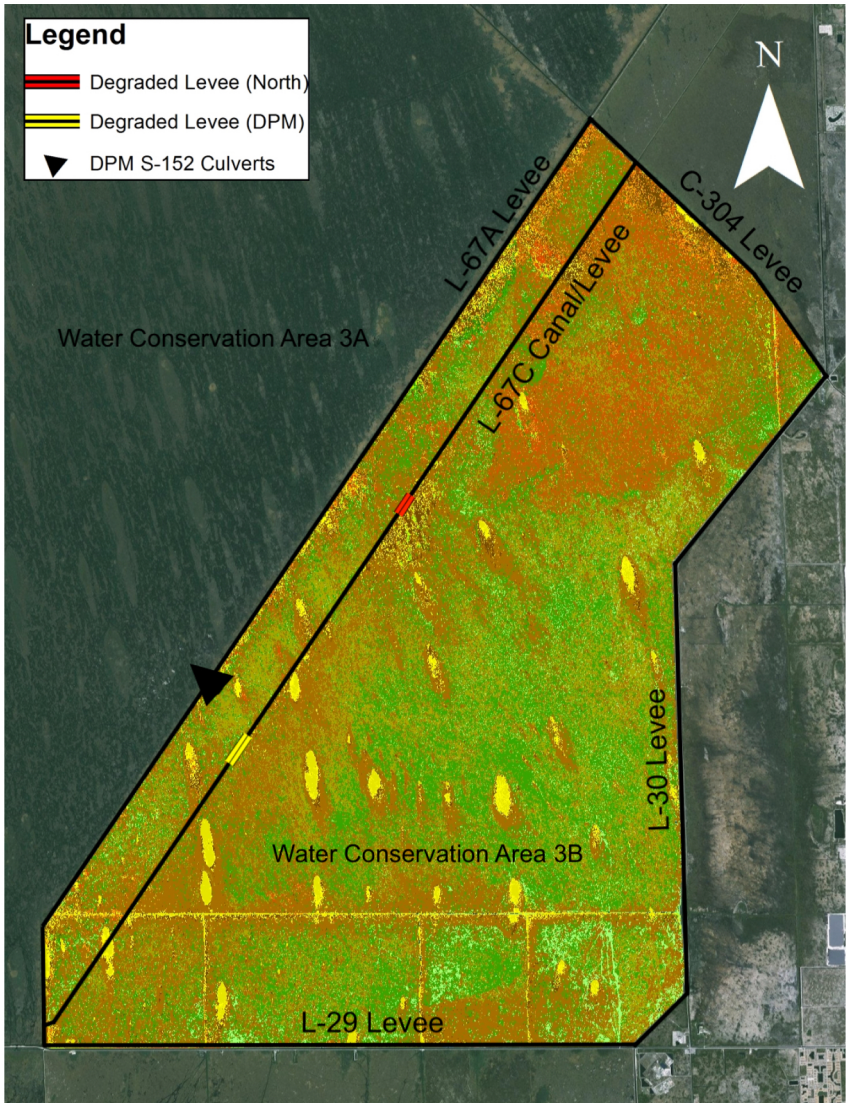

Floating Broadleaf

Graminoid Marsh

Sparse Graminoid Marsh

Sawgrass Marsh

Dense Sawgrass Marsh

Sparse Sawgrass Marsh

Sawgrass/Cattail Marsh

Cattail Marsh

Herbaceous Marsh

Shrub/Herbaceous Marsh Shrub/Tree Island

Canal 
Figure 2

A)

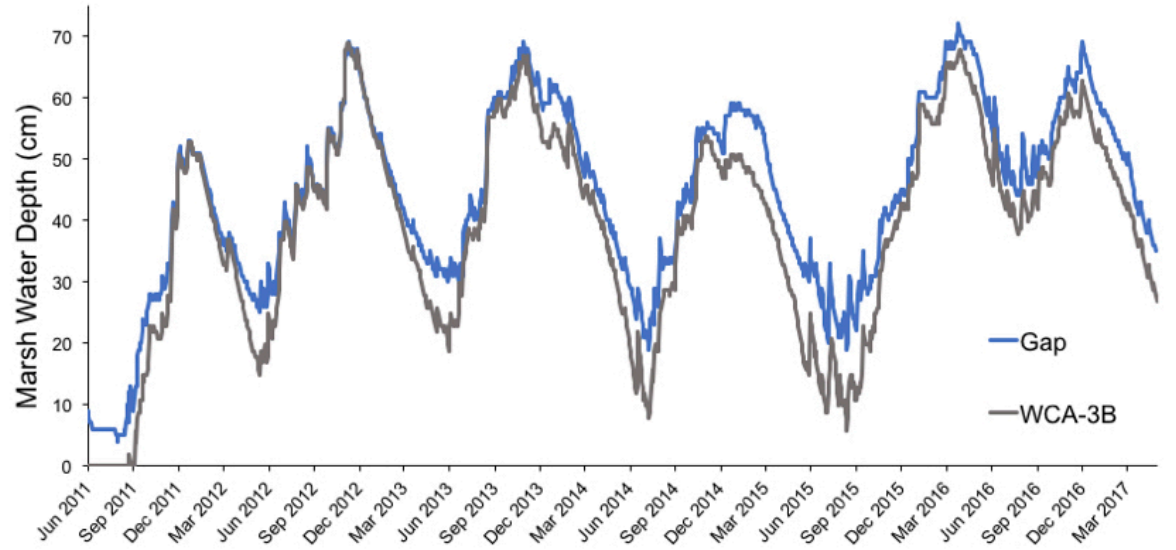

B)

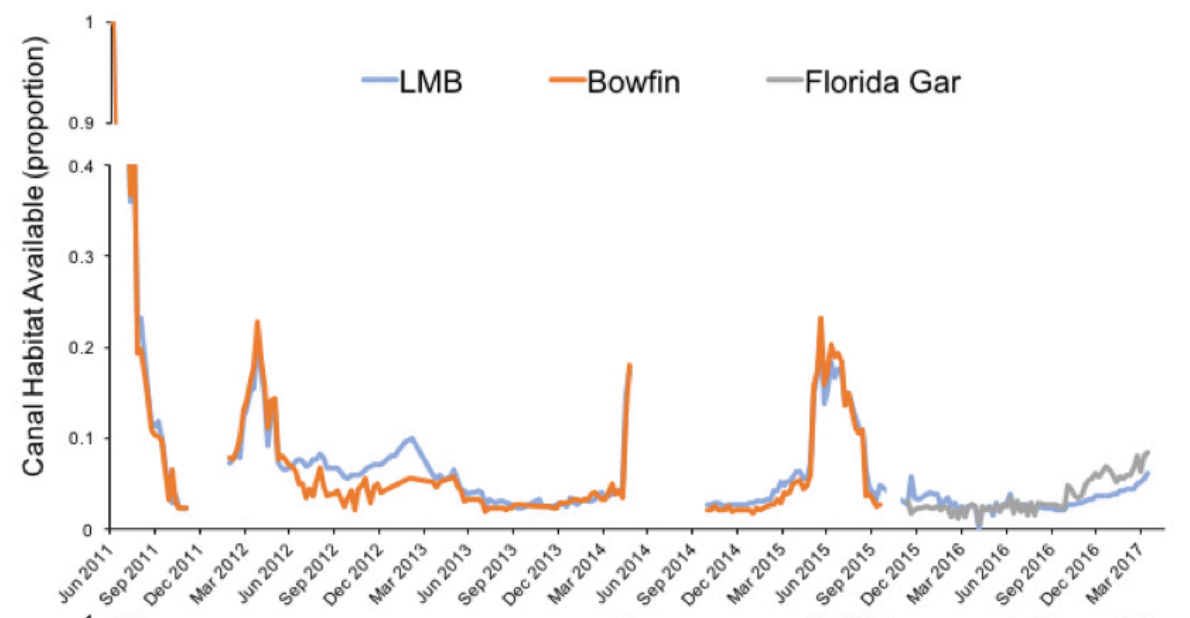

C)

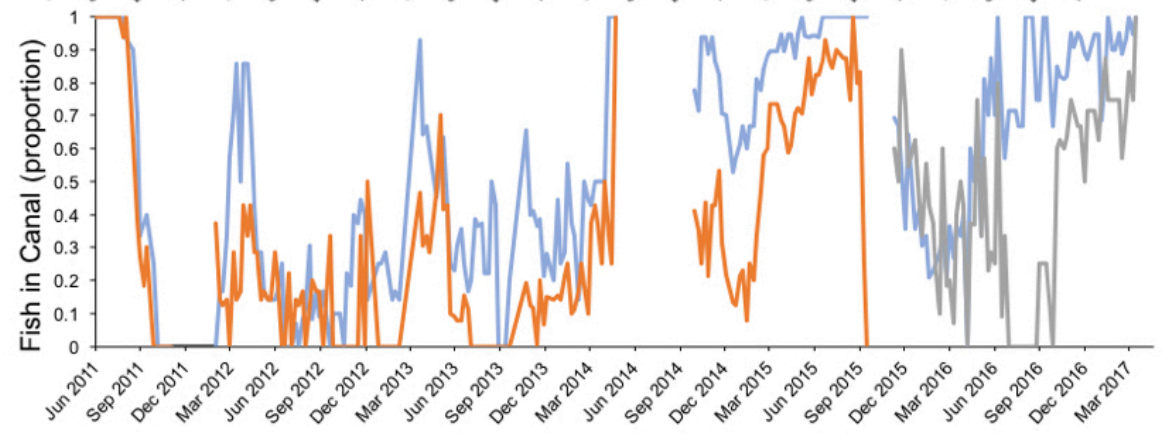

D)

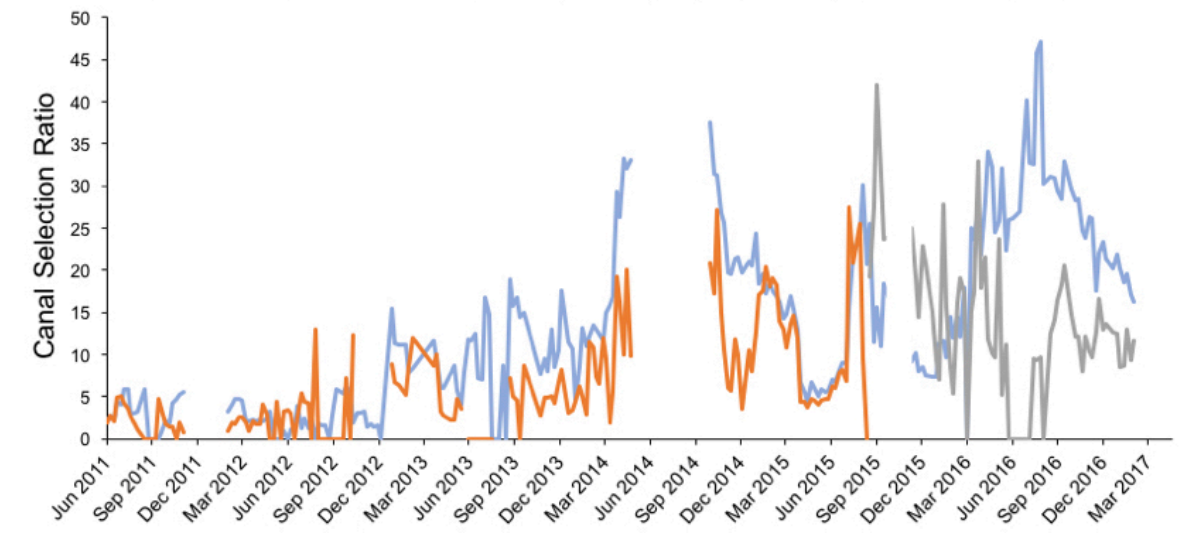


Figure 3
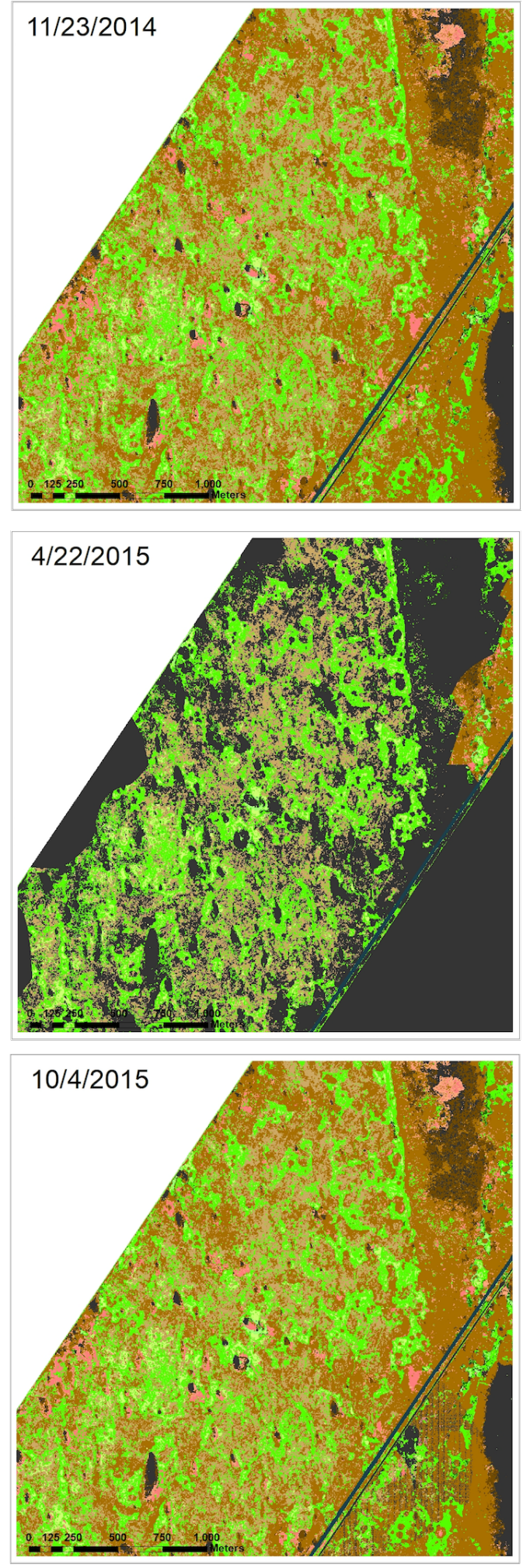
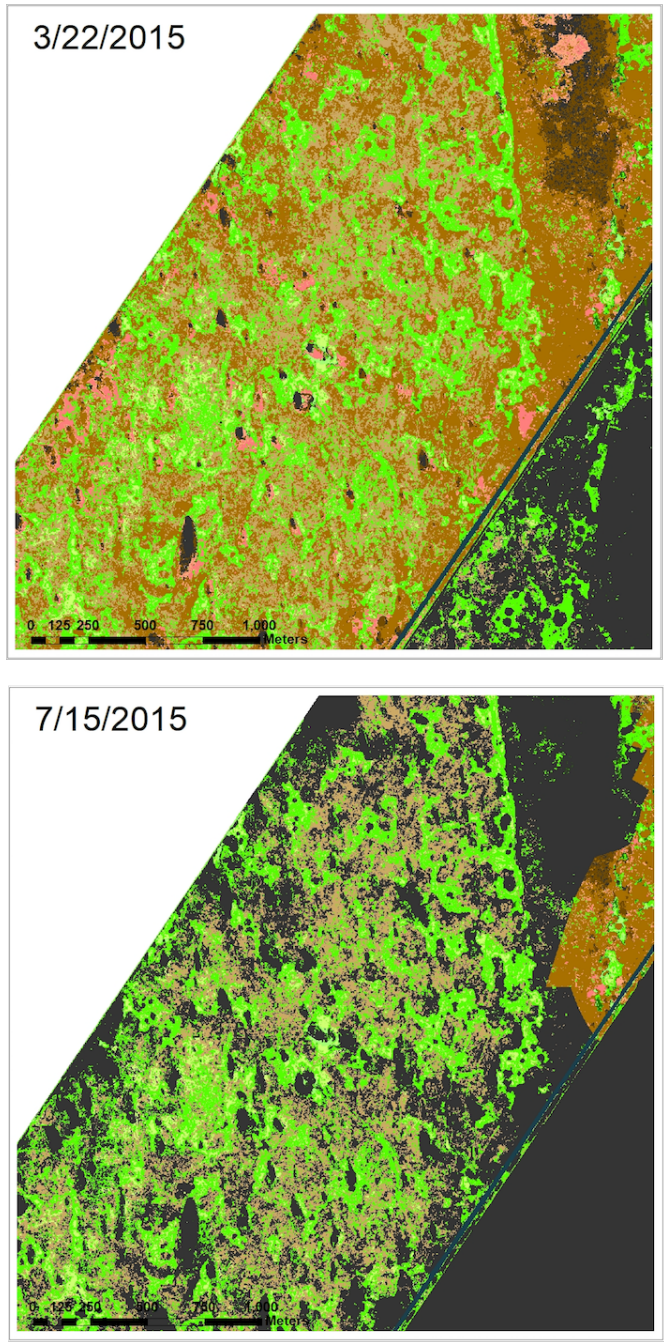

\section{Legend}

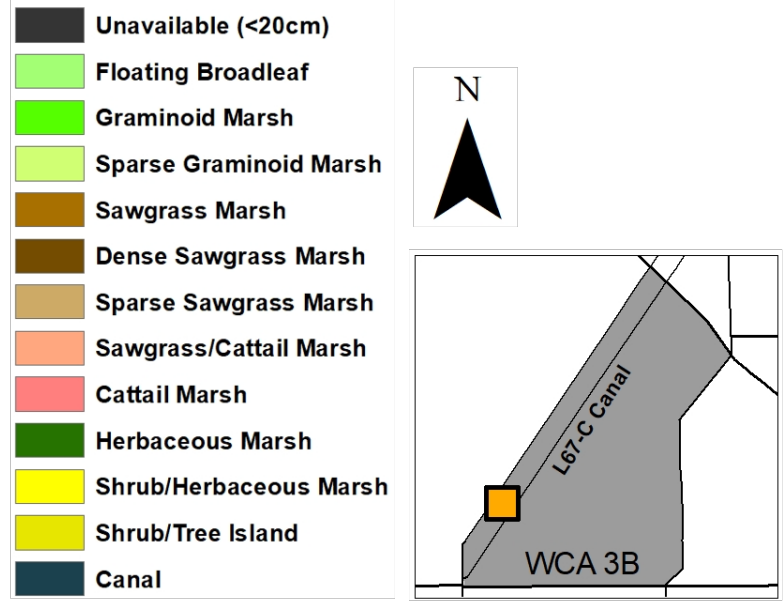


Figure 4

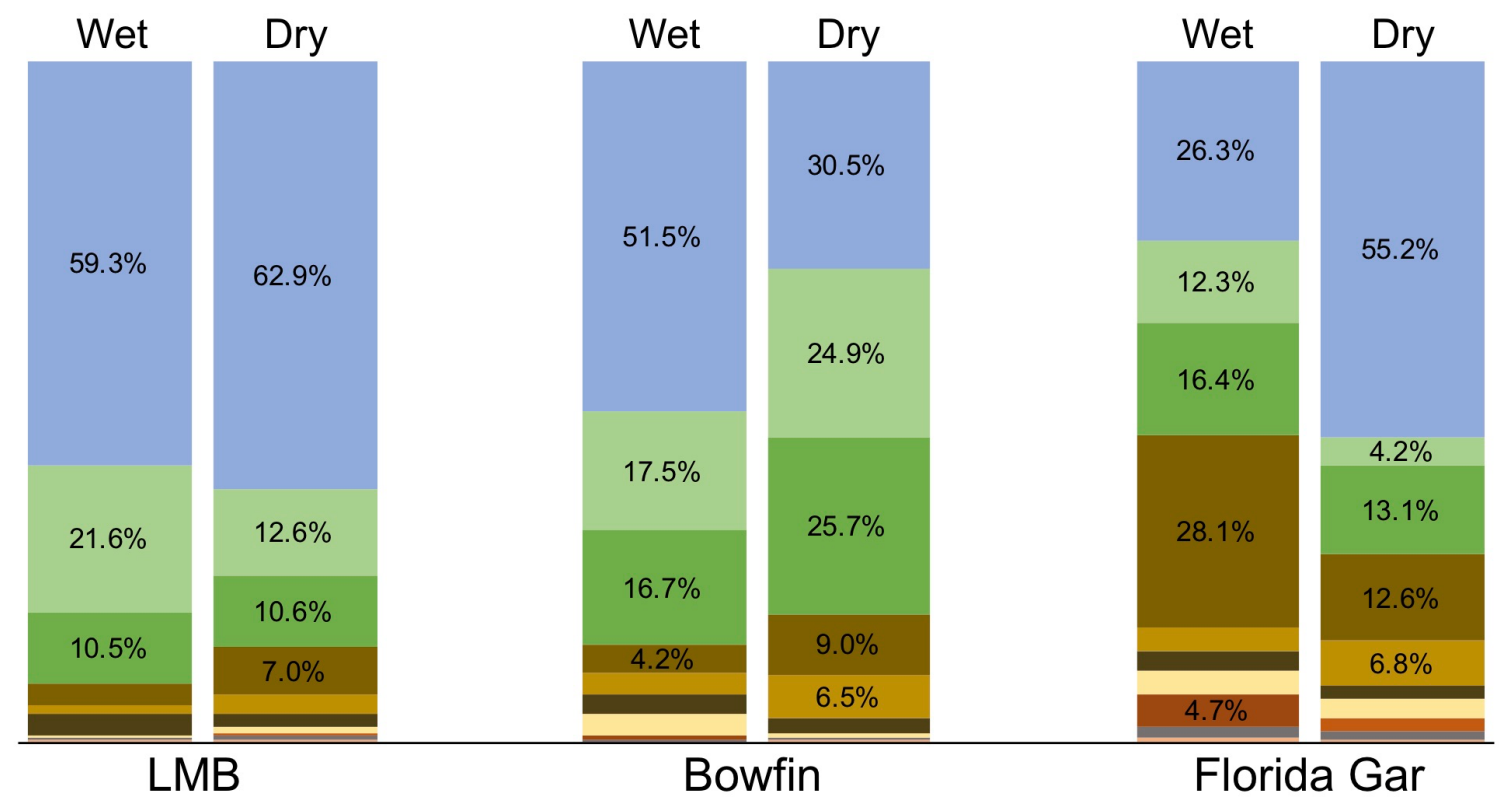

\begin{tabular}{|c|c|}
\hline Sawgrass/Cattail Marsh & - Cattail Marsh \\
\hline Herbaceous Marsh & Dense Sawgrass Marsh \\
\hline Floating Broadleaf & - Sparse Graminoid Marsh \\
\hline -Sawgr & - Graminoid Marsh \\
\hline Sparse Sawgrass Marsh & =Canal \\
\hline
\end{tabular}


Figure 5
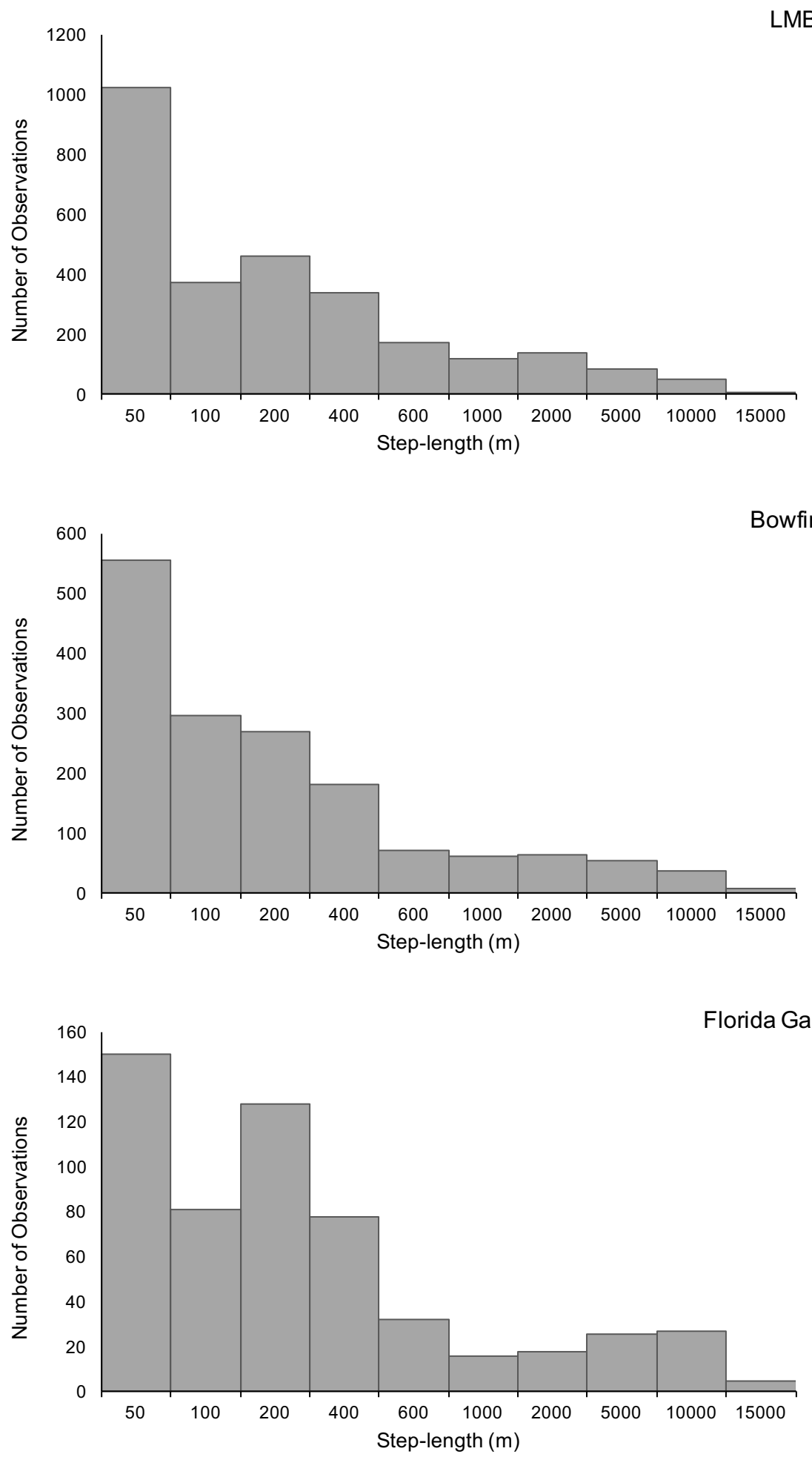
Figure 6
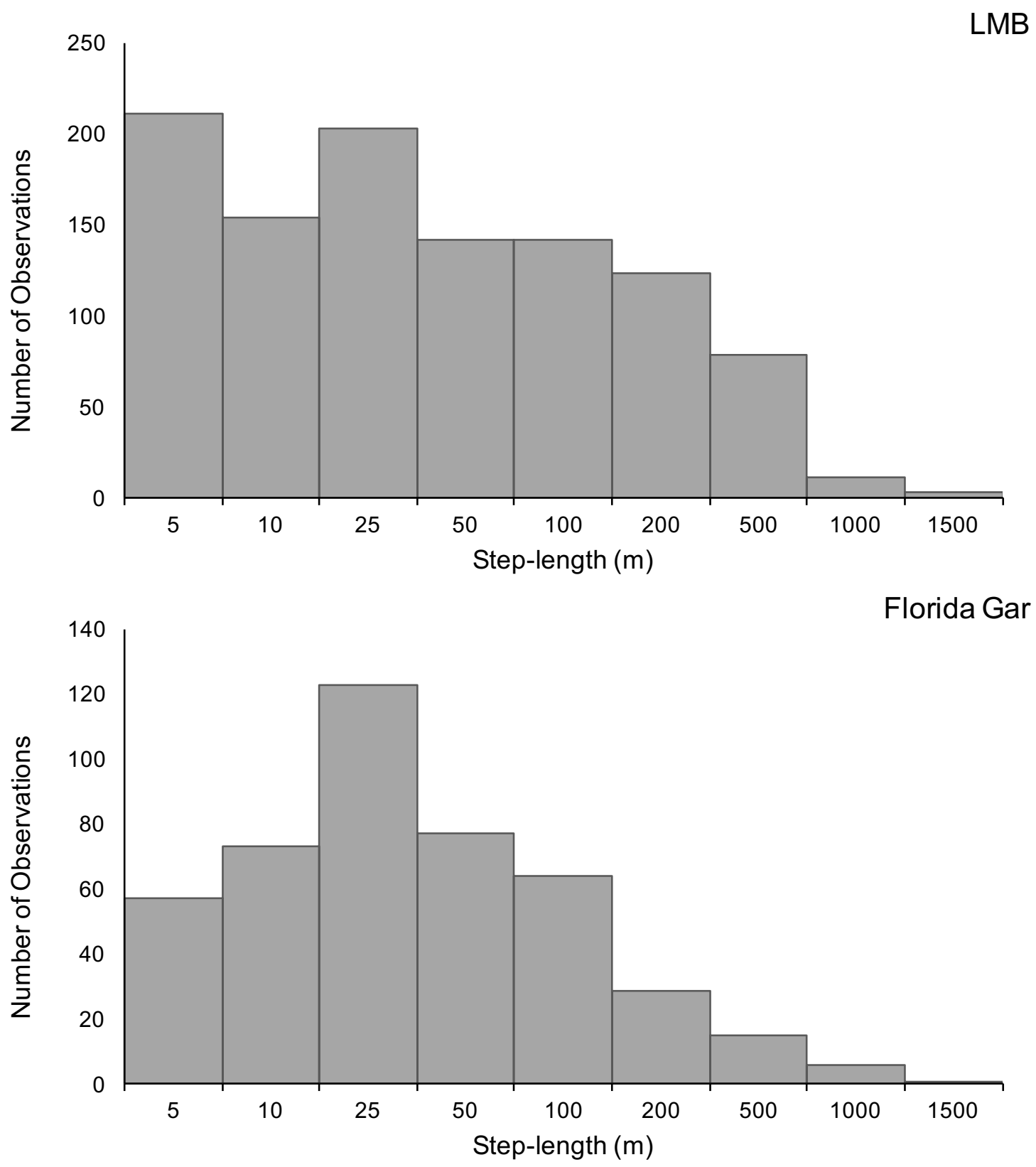
Figure 7

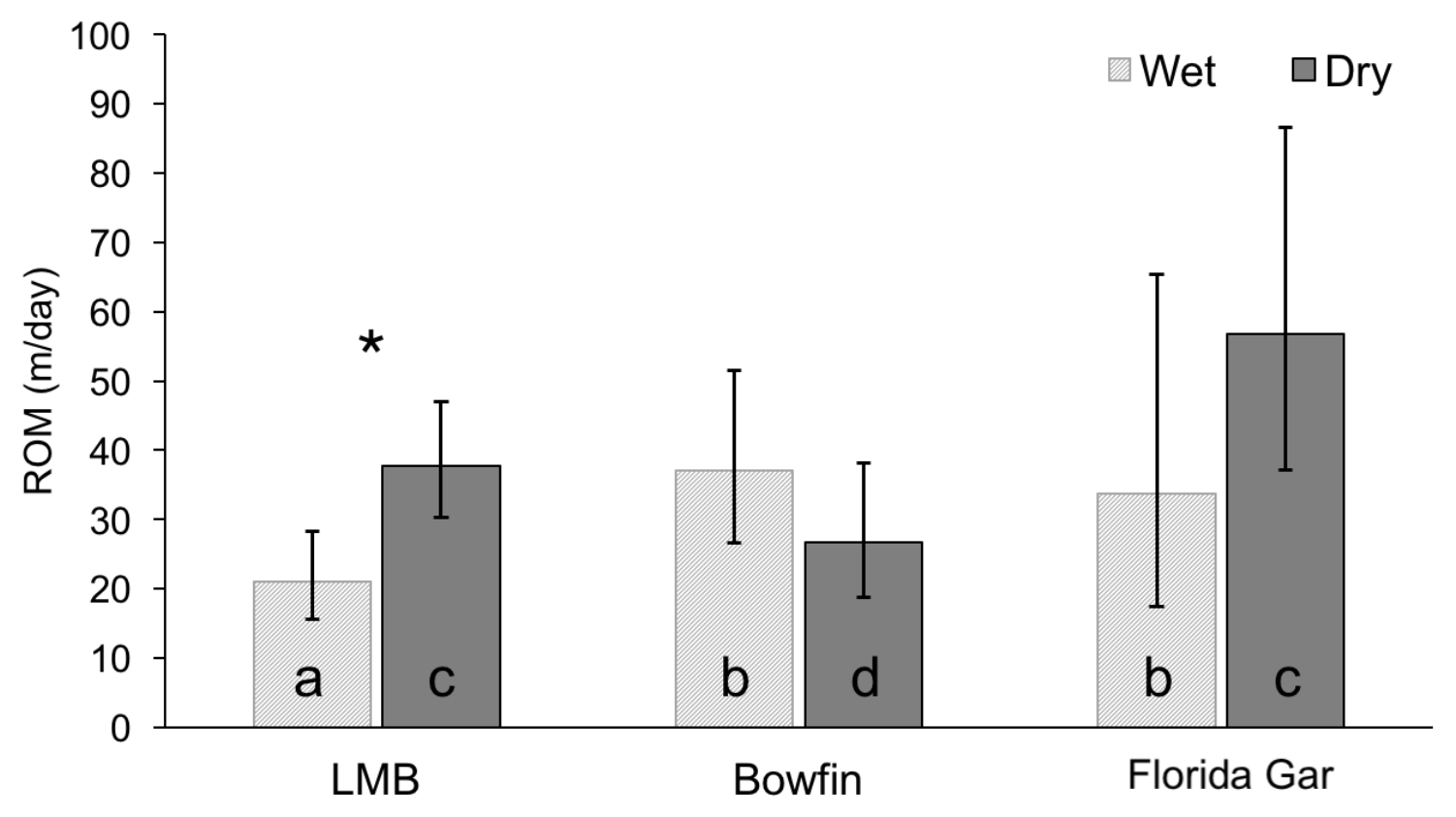




\section{Figure 8}

A)

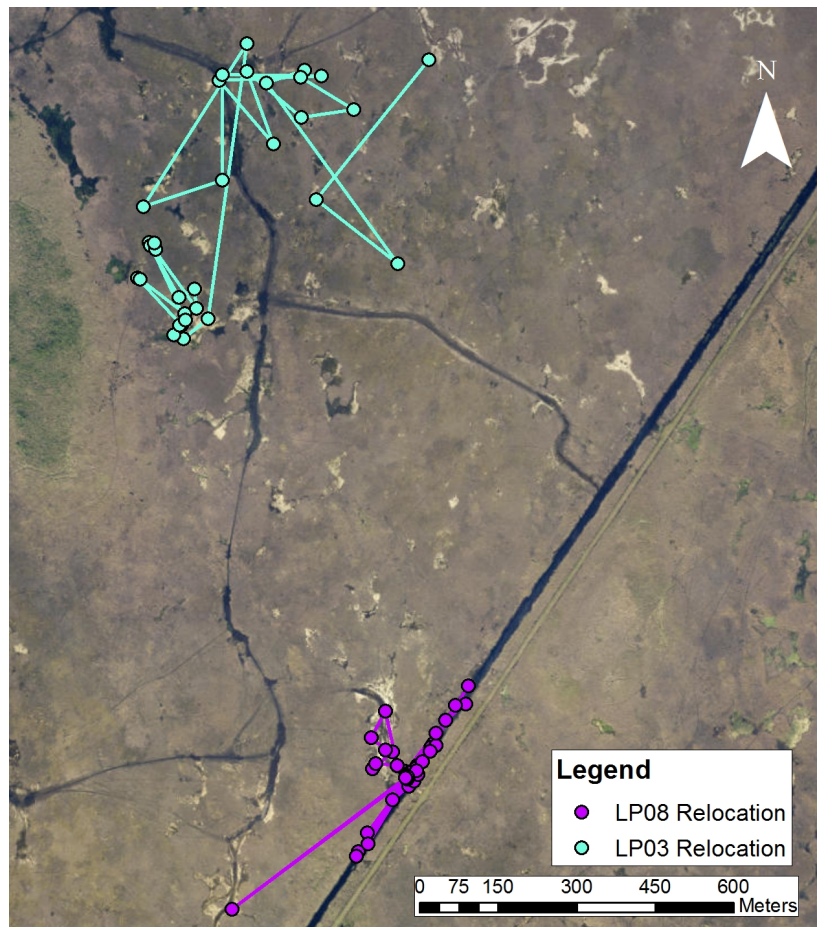

B)

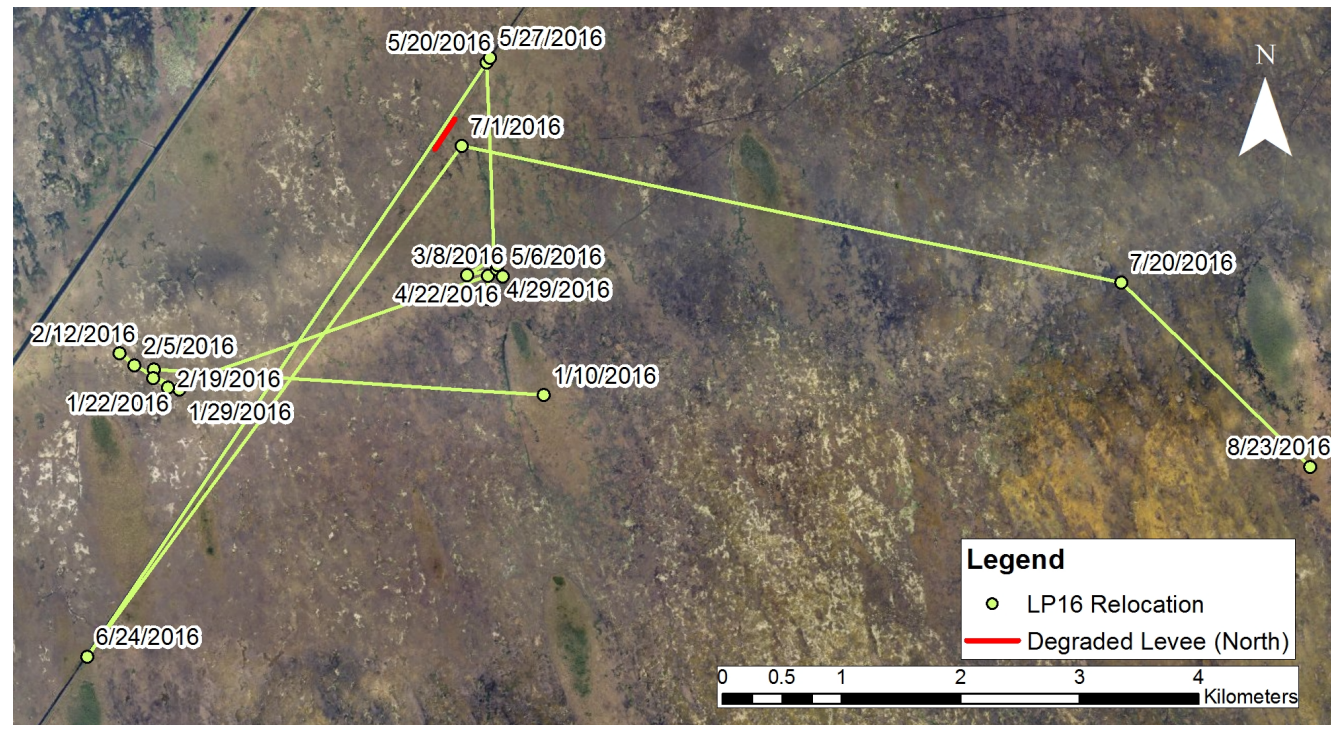




\section{Appendix}

\begin{tabular}{|c|c|c|c|c|c|c|c|c|c|}
\hline Batch & Date & Tag Size $(\mathrm{g})$ & Species & ID & Length (SL) & Time In MS-222 (min) & Surgery Time (min) & Recovery Time (min) & Number of Sutures \\
\hline & 12011 May & 3.9 & M. salmoides & MS01 & 29 & 15 & 7 & 5 & 3 \\
\hline & 12011 May & 3.9 & M. salmoides & MS02 & 26 & 3 & 6 & 5 & 3 \\
\hline & 12011 May & 3.9 & M. salmoides & MS03 & 28 & 4 & 8 & 4 & 5 \\
\hline & 12011 May & 2.9 & M. salmoides & MS05 & 30 & 5 & 19 & 26 & 3 \\
\hline & 12011 May & 3.9 & M. salmoides & MS06 & 26 & 8 & 6 & 6 & 3 \\
\hline & 12011 May & 2.9 & M. salmoides & MS07 & 27 & 4 & 6 & 6 & 2 \\
\hline & 12011 May & 2.9 & M. salmoides & MS08 & 24.5 & 11 & 6 & 4 & 3 \\
\hline & 12011 May & 2.9 & M. salmoides & MS09 & 27 & 8 & 6 & 10 & 3 \\
\hline & 12011 May & 2.9 & M. salmoides & MS10 & 23 & 8 & 6 & 9 & 3 \\
\hline & 12011 May & 2.9 & M. salmoides & MS11 & 26 & 18 & 5 & 11 & 3 \\
\hline & 22011 July & 3.9 & M. salmoides & MS12 & 26 & 7 & 6 & 11 & 3 \\
\hline & 22011 July & 3.9 & M. salmoides & MS13 & 29.5 & 4 & 4 & . & 2 \\
\hline & 22011 July & 3.9 & M. salmoides & MS14 & 27.5 & 6 & 4 & 4 & 2 \\
\hline & 22011 July & 2.9 & M. salmoides & MS15 & 32 & 12 & 4 & 6 & 2 \\
\hline & 22011 July & 2.9 & M. salmoides & MS16 & 30 & 8 & 7 & 5 & 3 \\
\hline & 22011 July & 2.9 & M. salmoides & MS17 & 39 & 6 & 6 & 11 & 2 \\
\hline & 22011 July & 2.9 & M. salmoides & MS18 & 26.5 & 11 & 5 & 4 & 2 \\
\hline & 22011 July & 2.9 & M. salmoides & MS19 & 25.5 & 3 & 8 & 5 & 3 \\
\hline & 22011 July & 2.9 & M. salmoides & MS20 & 30 & 4 & 4 & 4 & 2 \\
\hline & 22011 July & 2.9 & M. salmoides & MS21 & 28 & 4 & 5 & 2 & 2 \\
\hline & 32012 Jan & 3.9 & M. salmoides & MS22 & 26.5 & 5 & 6 & 10 & 3 \\
\hline & 32012 Jan & 3.9 & M. salmoides & MS23 & 29.8 & 12 & 6 & 4 & 3 \\
\hline & 32012 Jan & 3.9 & M. salmoides & MS24 & 35.3 & 2 & 6 & 3 & 3 \\
\hline & $32012 \mathrm{Feb}$, & 3.9 & M. salmoides & MS25 & 35.2 & 6 & 4 & . & 2 \\
\hline & 32012 Feb. & 3.9 & M. salmoides & MS26 & 28.6 & 7 & 4 & 5 & 2 \\
\hline & $32012 \mathrm{Feb}$ & 3.9 & M. salmoides & MS27 & 30 & 10 & 4 & 4 & 3 \\
\hline & 32012 Feb. & 3.9 & M. salmoides & MS28 & 28.7 & 5 & 7 & 3 & 3 \\
\hline & 42012 June & 3.9 & M. salmoides & MS29 & 29.5 & 22 & 8 & 23 & 2 \\
\hline & 42012 June & 3.9 & M. salmoides & MS30 & 34.5 & 4 & 4 & 4 & 2 \\
\hline & 42012 June & 3.9 & M. salmoides & MS31 & 28 & 5 & 4 & 12 & 3 \\
\hline & 42012 June & 3.9 & M. salmoides & MS32 & 32.5 & 3 & 5 & 14 & 2 \\
\hline & 4 2012 June & 3.9 & M. salmoides & MS33 & 27 & 5 & 4 & 3 & 2 \\
\hline & 42012 June & 3.9 & M. salmoides & MS34 & 28 & 2 & 4 & 10 & 2 \\
\hline & 42012 June & 3.9 & M. salmoides & MS35 & 36.5 & 3 & 3 & 9 & 2 \\
\hline & 42012 June & 3.9 & M. salmoides & MS36 & 27 & 8 & 3 & 10 & 2 \\
\hline & 42012 June & 3.9 & M. salmoides & MS37 & 29 & 2 & 6 & 7 & 3 \\
\hline & 42012 June & 3.9 & M. salmoides & MS38 & 35 & 10 & 9 & 5 & 3 \\
\hline & 42012 June & 3.9 & M. salmoides & MS39 & 30.5 & 3 & 5 & 4 & 2 \\
\hline & 42012 June & 3.9 & M. salmoides & MS40 & 28.5 & 4 & 3 & 7 & 2 \\
\hline & 42012 June & 3.9 & M. salmoides & MS41 & 32 & 4 & 6 & 4 & 3 \\
\hline & 52013 Mar. & 3.9 & M. salmoides & MS42 & 31.2 & 7 & 5 & 7 & 2 \\
\hline & 52013 Mar. & 3.9 & M. salmoides & MS43 & 29.7 & 7 & 7 & 3 & 2 \\
\hline & 52013 Mar. & 3.9 & M. salmoides & MS44 & 33.8 & 14 & 5 & 4 & 2 \\
\hline & 52013 Mar. & 3.9 & M. salmoides & MS45 & 32.2 & 5 & 5 & 3 & 2 \\
\hline & 52013 Mar. & 3.9 & M. salmoides & MS46 & 42.3 & 9 & 6 & 15 & 3 \\
\hline & 52013 Mar. & 3.9 & M. salmoides & MS47 & 41 & 6 & 5 & 25 & 2 \\
\hline & 52013 Mar. & 3.9 & M. salmoides & MS48 & 42.1 & 4 & 5 & 3 & 2 \\
\hline & 52013 Mar. & 3.9 & M. salmoides & MS49 & 29 & 6 & 5 & 12 & 2 \\
\hline & 52013 Mar. & 3.9 & M. salmoides & MS50 & 32.8 & 4 & 5 & 3 & 2 \\
\hline & 52013 Mar. & 3.9 & M. salmoides & MS51 & 29.7 & 4 & 5 & 4 & 3 \\
\hline & 52013 Mar. & 3.9 & M. salmoides & MS52 & 31.5 & 5 & 5 & 5 & 2 \\
\hline & 52013 Mar. & 3.9 & M. salmoides & MS53 & 27.4 & 5 & 6 & 4 & 2 \\
\hline & 52013 Mar. & 3.9 & M. salmoides & MS54 & 31.9 & 4 & 5 & 10 & 3 \\
\hline & 52013 Mar. & 3.9 & M. salmoides & MS55 & 37.9 & 4 & 5 & 2 & 2 \\
\hline & 52013 Mar. & 3.9 & M. salmoides & MS56 & 37.8 & 4 & 5 & 7 & 2 \\
\hline & 52013 Mar. & 3.9 & M. salmoides & MS57 & 35.3 & 11 & 5 & 3 & 3 \\
\hline & 52013 Mar. & 3.9 & M. salmoides & MS58 & 38.1 & 4 & 5 & 10 & 3 \\
\hline & 52013 Mar. & 3.9 & M. salmoides & MS59 & 29.2 & 5 & 5 & 2 & 3 \\
\hline & 52013 Mar. & 3.9 & M. salmoides & MS60 & 28.6 & 3 & 5 & 2 & 3 \\
\hline & 52013 Mar. & 3.9 & M. salmoides & MS61 & 30.8 & 6 & 5 & 3 & 3 \\
\hline & 62013 Oct. & 3.9 & M. salmoides & MS62 & 41 & 3 & 5 & 6 & 2 \\
\hline & 62013 Oct. & 3.9 & M. salmoides & MS63 & 27.9 & 4 & 5 & 10 & 2 \\
\hline & 62013 Oct. & 3.9 & M. salmoides & MS64 & 27 & 4 & 5 & 1 & 2 \\
\hline & 62013 Oct. & 3.9 & M. salmoides & MS65 & 28.8 & 4 & 6 & 1 & 3 \\
\hline & 62013 Oct. & 3.9 & M. salmoides & MS66 & 25.4 & 15 & 5 & 1 & 2 \\
\hline & 62013 Oct. & 3.9 & M. salmoides & MS67 & 42.8 & 9 & 4 & 3 & 2 \\
\hline & 62013 Oct. & 3.9 & M. salmoides & MS68 & 25.5 & 11 & 7 & 2 & 3 \\
\hline & 62013 Oct. & 3.9 & M. salmoides & MS69 & 30.5 & 3 & 5 & 1 & 2 \\
\hline & 62013 Oct. & 3.9 & M. salmoides & MS70 & 43.4 & 4 & 6 & 8 & 3 \\
\hline
\end{tabular}


Appendix (continued)

\begin{tabular}{|c|c|c|c|c|}
\hline 62013 Oct. & 3.9 & M. salmoides & MS71 & 28.2 \\
\hline 62013 Oct. & 3.9 & M. salmoides & MS72 & 27.2 \\
\hline 62013 Oct. & 3.9 & M. salmoides & MS73 & 42.4 \\
\hline 62013 Oct. & 3.9 & M. salmoides & MS74 & 39.5 \\
\hline 62013 Oct. & 3.9 & M. salmoides & MS75 & 38 \\
\hline 62013 Oct. & 3.9 & M. salmoides & MS76 & 31.2 \\
\hline 62013 Oct. & 3.9 & M. salmoides & MS77 & 36.6 \\
\hline 62013 Oct. & 3.9 & M. salmoides & MS78 & 30.9 \\
\hline 62013 Oct. & 3.9 & M. salmoides & MS79 & 26.2 \\
\hline 62013 Oct. & 3.9 & M. salmoides & MS80 & 27.8 \\
\hline 62013 Oct. & 3.9 & M. salmoides & MS81 & 28.1 \\
\hline 72014 Sept. & 8.5 & M. salmoides & MS82 & 43.2 \\
\hline 72014 Sept. & 8.5 & M. salmoides & MS83 & 45 \\
\hline 72014 Sept. & 8.5 & M. salmoides & MS84 & 35.2 \\
\hline 72014 Sept. & 8.5 & M. salmoides & MS85 & 30.4 \\
\hline 72014 Sept. & 8.5 & M. salmoides & MS86 & 37.3 \\
\hline 72014 Sept. & 8.5 & M. salmoides & MS87 & 35.1 \\
\hline 72014 Sept. & 8.5 & M. salmoides & MS88 & 29.7 \\
\hline 72014 Sept. & 8.5 & M. salmoides & MS89 & 32.8 \\
\hline 72014 Sept. & 8.5 & M. salmoides & MS90 & 32.7 \\
\hline 72014 Sept. & 8.5 & M. salmoides & MS91 & 42.7 \\
\hline 72014 Sept. & 8.5 & M. salmoides & MS92 & 42.5 \\
\hline 72014 Sept. & 8.5 & M. salmoides & MS93 & 33 \\
\hline 72014 Sept. & 8.5 & M. salmoides & MS94 & 34.9 \\
\hline 72014 Sept. & 8.5 & M. salmoides & MS95 & 39 \\
\hline 72014 Sept. & 8.5 & M. salmoides & MS96 & 45 \\
\hline 72014 Oct. & 8.5 & M. salmoides & MS97 & 29.6 \\
\hline 72014 Oct. & 8.5 & M. salmoides & MS98 & 34 \\
\hline 72014 Oct. & 8.5 & M. salmoides & MS99 & 28.8 \\
\hline 72014 Oct. & 8.5 & M. salmoides & MS100 & 30 \\
\hline 72014 Oct. & 8.5 & M. salmoides & MS101 & 29.9 \\
\hline 82015 Nov. & 8.5 & M. salmoides & MS102 & 37.5 \\
\hline 82015 Nov. & 8.5 & M. salmoides & MS103 & 38 \\
\hline 82015 Nov. & 8.5 & M. salmoides & MS104 & 30 \\
\hline 82015 Nov. & 8.5 & M. salmoides & MS105 & 36.4 \\
\hline 82015 Nov. & 8.5 & M. salmoides & MS106 & 37.4 \\
\hline 82015 Nov. & 8.5 & M. salmoides & MS107 & 41 \\
\hline 82015 Nov. & 8.5 & M. salmoides & MS108 & 40.8 \\
\hline 82015 Nov. & 8.5 & M. salmoides & MS109 & 35.8 \\
\hline 82015 Nov. & 8.5 & M. salmoides & MS110 & 37.4 \\
\hline 82015 Nov. & 8.5 & M. salmoides & MS111 & 38.1 \\
\hline 82015 Nov. & 8.5 & M. salmoides & MS112 & 42 \\
\hline 82015 Nov. & 8.5 & M. salmoides & MS113 & 35.3 \\
\hline 82015 Nov. & 8.5 & M. salmoides & MS114 & 34.2 \\
\hline 82015 Nov. & 8.5 & M. salmoides & MS115 & 33.8 \\
\hline 82015 Nov. & 8.5 & M. salmoides & MS116 & 36.8 \\
\hline 82015 Nov. & 8.5 & M. salmoides & MS117 & 31.6 \\
\hline 82015 Nov. & 8.5 & M. salmoides & MS118 & 36.8 \\
\hline 82015 Nov. & 8.5 & M. salmoides & MS119 & 30.8 \\
\hline 82015 Nov. & 8.5 & M. salmoides & MS120 & 34.4 \\
\hline 82015 Nov. & 8.5 & M. salmoides & MS121 & 33.4 \\
\hline 92016 Sept. & 7.9 & M. salmoides & MS122 & 44.5 \\
\hline 92016 Sept. & 7.9 & M. salmoides & MS123 & 30.9 \\
\hline 92016 Sept. & 7.9 & M. salmoides & MS124 & 31 \\
\hline 92016 Sept. & 7.9 & M. salmoides & MS125 & 29.9 \\
\hline 92016 Sept. & 7.9 & M. salmoides & MS126 & 28.4 \\
\hline 92016 Sept. & 7.9 & M. salmoides & MS127 & 30 \\
\hline 92016 Sept. & 7.9 & M. salmoides & MS128 & 41.3 \\
\hline 92016 Sept. & 7.9 & M. salmoides & MS129 & 43.7 \\
\hline 92016 Sept. & 7.9 & M. salmoides & MS130 & 37.4 \\
\hline 92016 Sept. & 7.9 & M. salmoides & MS131 & 28.7 \\
\hline 92016 Oct. & 7.9 & M. salmoides & MS132 & 34.5 \\
\hline 92016 Oct. & 7.9 & M. salmoides & MS133 & 43 \\
\hline 92016 Oct. & 7.9 & M. salmoides & MS134 & 42.4 \\
\hline 92016 Oct. & 7.9 & M. salmoides & MS135 & 31.5 \\
\hline 92016 Oct. & 7.9 & M. salmoides & MS136 & 32.1 \\
\hline 92016 Oct. & 7.9 & M. salmoides & MS137 & 36.7 \\
\hline 92016 Oct. & 7.9 & M. salmoides & MS138 & 33.4 \\
\hline 92016 Oct. & 7.9 & M. salmoides & MS139 & 42.4 \\
\hline 92016 Oct. & 7.9 & M. salmoides & MS140 & 44 \\
\hline
\end{tabular}

\begin{tabular}{|c|c|c|}
\hline 8 & 1 & 3 \\
\hline 7 & 3 & 3 \\
\hline 6 & 5 & 3 \\
\hline 6 & 3 & 3 \\
\hline 5 & 6 & 3 \\
\hline 6 & 2 & 3 \\
\hline 6 & 4 & 3 \\
\hline 6 & 4 & 3 \\
\hline 7 & 5 & 3 \\
\hline 6 & 4 & 3 \\
\hline 6 & 1 & 3 \\
\hline 7 & 1 & 4 \\
\hline 6 & 6 & 3 \\
\hline 6 & 2 & 3 \\
\hline 7 & 2 & 4 \\
\hline 6 & 2 & 4 \\
\hline 6 & 1 & 4 \\
\hline 6 & 2 & 3 \\
\hline 7 & 8 & 4 \\
\hline 6 & 10 & 4 \\
\hline 6 & 8 & 4 \\
\hline 5 & 2 & 4 \\
\hline 6 & 15 & 3 \\
\hline 6 & 7 & 3 \\
\hline 5 & 17 & 3 \\
\hline 6 & 6 & 3 \\
\hline 6 & 3 & 3 \\
\hline 5 & 5 & 3 \\
\hline 5 & 6 & 3 \\
\hline 6 & 1 & 3 \\
\hline 5 & 1 & . \\
\hline 7 & 5 & 5 \\
\hline 6 & 6 & 4 \\
\hline 5 & 1 & 4 \\
\hline 5 & 5 & 3 \\
\hline 5 & 3 & 3 \\
\hline 5 & 2 & 3 \\
\hline 5 & 2 & 3 \\
\hline 5 & 5 & 3 \\
\hline 5 & 2 & 3 \\
\hline 5 & 0 & 3 \\
\hline 5 & 0 & 3 \\
\hline 4 & 5 & 3 \\
\hline 4 & 6 & 3 \\
\hline 5 & 5 & 3 \\
\hline 5 & 2 & 3 \\
\hline 6 & 0 & 3 \\
\hline 5 & 10 & 3 \\
\hline 4 & 2 & 3 \\
\hline 5 & 2 & 3 \\
\hline 5 & 1 & 3 \\
\hline 8 & 7 & 3 \\
\hline 8 & 4 & 3 \\
\hline 8 & 14 & 2 \\
\hline 8 & 12 & 3 \\
\hline 8 & 9 & 3 \\
\hline 6 & 8 & 2 \\
\hline 8 & 4 & 3 \\
\hline 7 & 6 & 3 \\
\hline 6 & 5 & 2 \\
\hline 7 & 3 & 2 \\
\hline 7 & 5 & 3 \\
\hline 6 & 9 & 3 \\
\hline 5 & 7 & 2 \\
\hline 5 & 4 & 2 \\
\hline 7 & 3 & 2 \\
\hline 5 & 5 & 2 \\
\hline 4 & 3 & 2 \\
\hline 4 & 4 & 2 \\
\hline 5 & 2 & 2 \\
\hline
\end{tabular}


Appendix (continued)

\begin{tabular}{|c|c|c|c|c|}
\hline 92016 Oct. & 7.9 & M. salmoides & MS141 & 29.9 \\
\hline 12011 May & 3.9 & A. calva & AC01 & 45 \\
\hline 12011 May & 3.9 & A. calva & AC02 & 42 \\
\hline 12011 May & 3.9 & A. calva & AC03 & 38 \\
\hline 12011 May & 3.9 & A. calva & AC04 & 35 \\
\hline 12011 May & 3.9 & A. calva & AC05 & 37.5 \\
\hline 12011 May & 2.9 & A. calva & AC06 & 50 \\
\hline 12011 May & 2.9 & A. calva & AC07 & 52.5 \\
\hline 12011 May & 3.9 & A. calva & AC08 & 31.5 \\
\hline 12011 May & 2.9 & A. calva & AC09 & 37 \\
\hline 12011 May & 2.9 & A. calva & AC10 & 37 \\
\hline 22011 July & 3.9 & A. calva & AC11 & 39 \\
\hline 2 2011 July & 3.9 & A. calva & AC12 & 39.5 \\
\hline 22011 July & 3.9 & A. calva & AC13 & 45.5 \\
\hline 2 2011 July & 3.9 & A. calva & AC14 & 41.5 \\
\hline 2 2011 July & 3.9 & A. calva & AC15 & 39.5 \\
\hline 2 2011 July & 3.9 & A. calva & AC16 & 32.5 \\
\hline 2 2011 July & 3.9 & A. calva & AC17 & 47 \\
\hline 2 2011 July & 2.9 & A. calva & AC18 & 45 \\
\hline 2 2011 July & 2.9 & A. calva & AC19 & 47 \\
\hline 2 2011 July & 2.9 & A. calva & AC20 & 41 \\
\hline 32012 Jan. & 3.9 & A. calva & AC21 & 40 \\
\hline 3 2012 Jan. & 3.9 & A. calva & AC22 & 40.3 \\
\hline 3 2012 Jan. & 3.9 & A. calva & AC23 & 44.5 \\
\hline 3 2012 Jan. & 3.9 & A. calva & AC24 & 44.4 \\
\hline 32012 Jan. & 3.9 & A. calva & AC25 & 37.2 \\
\hline 32012 Jan. & 3.9 & A. calva & AC26 & 39.7 \\
\hline 32012 Feb. & 3.9 & A. calva & AC27 & 38.1 \\
\hline $32012 \mathrm{Feb}$. & 3.9 & A. calva & AC28 & 40.5 \\
\hline 32012 Feb. & 3.9 & A. calva & AC29 & 38.5 \\
\hline $32012 \mathrm{Feb}$. & 3.9 & A. calva & AC30 & 38.4 \\
\hline 32012 Feb. & 3.9 & A. calva & AC31 & 40.3 \\
\hline $32012 \mathrm{Feb}$. & 3.9 & A. calva & AC32 & 38.3 \\
\hline 32012 Feb. & 3.9 & A. calva & AC33 & 44.5 \\
\hline 42012 June & 3.9 & A. calva & AC30 & 41 \\
\hline 42012 June & 3.9 & A. calva & AC33 & 46 \\
\hline 42012 June & 3.9 & A. calva & AC34 & 53 \\
\hline 42012 June & 3.9 & A. calva & AC35 & 43 \\
\hline 42012 June & 3.9 & A. calva & AC36 & 52 \\
\hline 42012 June & 3.9 & A. calva & AC37 & 42.5 \\
\hline 42012 June & 3.9 & A. calva & AC38 & 54 \\
\hline 42012 June & 3.9 & A. calva & AC39 & 42 \\
\hline 42012 June & 3.9 & A. calva & AC40 & 41.5 \\
\hline 52013 Mar. & 3.9 & A. calva & AC41 & 44.8 \\
\hline 52013 Mar. & 3.9 & A. calva & AC42 & 39.7 \\
\hline 52013 Mar. & 3.9 & A. calva & AC43 & 36 \\
\hline 52013 Mar. & 3.9 & A. calva & AC44 & 45.6 \\
\hline 52013 Mar. & 3.9 & A. calva & AC45 & 38.6 \\
\hline 52013 Mar. & 3.9 & A. calva & AC46 & 37.8 \\
\hline 52013 Mar. & 3.9 & A. calva & AC47 & 38.1 \\
\hline 52013 Mar. & 3.9 & A. calva & AC48 & 39.3 \\
\hline 52013 Mar. & 3.9 & A. calva & AC49 & 43.7 \\
\hline 52013 Mar. & 3.9 & A. calva & AC50 & 52.6 \\
\hline 52013 Mar. & 3.9 & A. calva & AC51 & 42.5 \\
\hline 52013 Mar. & 3.9 & A. calva & AC52 & 40.2 \\
\hline 52013 Mar. & 3.9 & A. calva & AC53 & 48.4 \\
\hline 52013 Mar. & 3.9 & A. calva & AC54 & 43.5 \\
\hline 52013 Mar. & 3.9 & A. calva & AC55 & 46 \\
\hline 52013 Mar. & 3.9 & A. calva & AC56 & 42 \\
\hline 52013 Mar. & 3.9 & A. calva & AC57 & 39.2 \\
\hline 52013 Mar. & 3.9 & A. calva & AC58 & 50.3 \\
\hline 62013 Oct. & 3.9 & A. calva & AC59 & 38.8 \\
\hline 62013 Oct. & 3.9 & A. calva & AC60 & 36.4 \\
\hline 62013 Oct. & 3.9 & A. calva & AC61 & 52.5 \\
\hline 62013 Oct. & 3.9 & A. calva & AC62 & 43.1 \\
\hline 62013 Oct. & 3.9 & A. calva & AC63 & 43.3 \\
\hline 62013 Oct. & 3.9 & A. calva & AC64 & 40.6 \\
\hline 62013 Oct. & 3.9 & A. calva & AC65 & 46.1 \\
\hline 62013 Oct. & 3.9 & A. calva & AC66 & 42.3 \\
\hline 62013 Oct. & 3.9 & A. calva & AC67 & 43.2 \\
\hline
\end{tabular}

\begin{tabular}{|c|c|c|}
\hline 6 & 8 & 2 \\
\hline 14 & 16 & 3 \\
\hline 9 & 3 & 4 \\
\hline 8 & 5 & re-sutured; 3 \\
\hline 12 & 39 & 3 \\
\hline 11 & 5 & 4 \\
\hline 7 & 18 & re-sutured; 3 \\
\hline 7 & 20 & 3 \\
\hline 9 & 6 & 3 \\
\hline 9 & 19 & 3 \\
\hline 4 & 20 & re-sutured; 2 \\
\hline 8 & 4 & 2 \\
\hline 8 & 8 & 3 \\
\hline 6 & 17 & 2 \\
\hline 5 & 10 & 2 \\
\hline 6 & 7 & 2 \\
\hline 4 & . & 2 \\
\hline 8 & 12 & 2 \\
\hline 6 & 11 & 2 \\
\hline 6 & 3 & 2 \\
\hline 10 & 5 & 3 \\
\hline 6 & 8 & 3 \\
\hline 7 & 3 & 3 \\
\hline 7 & 4 & 3 \\
\hline 7 & 6 & 3 \\
\hline 4 & 4 & 3 \\
\hline 4 & 5 & 3 \\
\hline 8 & 4 & 2 \\
\hline 8 & 14 & 2 \\
\hline 7 & 6 & 2 \\
\hline 5 & 4 & 2 \\
\hline 3 & 7 & 2 \\
\hline 6 & 3 & 3 \\
\hline 3 & 8 & 3 \\
\hline 6 & 9 & Re-tagged; 2 \\
\hline 10 & 3 & Re-tagged; 2 \\
\hline 3 & 12 & 2 \\
\hline 7 & 4 & 2 \\
\hline 5 & 14 & 2 \\
\hline 4 & 5 & 2 \\
\hline 7 & 5 & 2 \\
\hline 5 & 8 & 3 \\
\hline 4 & 5 & 2 \\
\hline 7 & 3 & 2 \\
\hline 6 & 5 & 2 \\
\hline 7 & 2 & 2 \\
\hline 6 & 1 & 2 \\
\hline 6 & 2 & 2 \\
\hline 6 & 1 & 2 \\
\hline 5 & 1 & 2 \\
\hline 6 & 2 & 2 \\
\hline 6 & 4 & 2 \\
\hline 7 & 10 & 3 \\
\hline 5 & 3 & 2 \\
\hline 7 & 2 & 2 \\
\hline 5 & 4 & 3 \\
\hline 5 & 1 & 2 \\
\hline 7 & 2 & 2 \\
\hline 4 & 2 & 2 \\
\hline 6 & 2 & 2 \\
\hline 7 & 1 & 3 \\
\hline 5 & . & 3 \\
\hline 5 & . & 2 \\
\hline 8 & . & 3 \\
\hline 4 & . & 2 \\
\hline 7 & . & 2 \\
\hline 5 & 5 & 2 \\
\hline 5 & 4 & 2 \\
\hline 6 & . & 2 \\
\hline 6 & 1 & 3 \\
\hline
\end{tabular}


Appendix (continued)

\begin{tabular}{|c|c|c|c|}
\hline 62013 Oct. & 3.9 & A. calva & AC68 \\
\hline 62013 Oct. & 3.9 & A. calva & AC69 \\
\hline 62013 Oct. & 3.9 & A. calva & AC70 \\
\hline 62013 Oct. & 3.9 & A. calva & AC71 \\
\hline 62013 Oct. & 3.9 & A. calva & AC72 \\
\hline 62013 Oct. & 3.9 & A. calva & AC73 \\
\hline 62013 Oct. & 3.9 & A. calva & AC74 \\
\hline 62013 Oct. & 3.9 & A. calva & AC75 \\
\hline 62013 Oct. & 3.9 & A. calva & AC76 \\
\hline 62013 Oct. & 3.9 & A. calva & AC77 \\
\hline 62013 Oct. & 3.9 & A. calva & AC78 \\
\hline 72014 Sept. & 8.5 & A. calva & AC79 \\
\hline 72014 Sept. & 8.5 & A. calva & AC80 \\
\hline 72014 Sept. & 8.5 & A. calva & AC81 \\
\hline 72014 Sept. & 8.5 & A. calva & AC82 \\
\hline 72014 Sept. & 8.5 & A. calva & AC83 \\
\hline 72014 Sept. & 8.5 & A. calva & AC84 \\
\hline 72014 Sept. & 8.5 & A. calva & AC85 \\
\hline 72014 Sept. & 8.5 & A. calva & AC86 \\
\hline 72014 Sept. & 8.5 & A. calva & AC87 \\
\hline 72014 Sept. & 8.5 & A. calva & AC88 \\
\hline 72014 Sept. & 8.5 & A. calva & AC89 \\
\hline 72014 Sept. & 8.5 & A. calva & AC90 \\
\hline 72014 Sept. & 8.5 & A. calva & AC91 \\
\hline 72014 Sept. & 8.5 & A. calva & AC92 \\
\hline 72014 Sept. & 8.5 & A. calva & AC93 \\
\hline 72014 Sept. & 8.5 & A. calva & AC94 \\
\hline 72014 Sept. & 8.5 & A. calva & AC95 \\
\hline 72014 Sept. & 8.5 & A. calva & AC96 \\
\hline 72014 Sept. & 8.5 & A. calva & AC97 \\
\hline 72014 Oct. & 8.5 & A. calva & AC98 \\
\hline 82015 Nov. & 8.5 & L. platyrhincus & LP01 \\
\hline 82015 Nov. & 8.5 & L. platyrhincus & LP02 \\
\hline 82015 Nov. & 8.5 & L. platyrhincus & LP03 \\
\hline 82015 Nov. & 8.5 & L. platyrhincus & LP04 \\
\hline 82015 Nov. & 8.5 & L. platyrhincus & LP05 \\
\hline 82015 Nov. & 8.5 & L. platyrhincus & LP06 \\
\hline 82015 Nov. & 8.5 & L. platyrhincus & LP07 \\
\hline 82015 Nov. & 8.5 & L. platyrhincus & LP08 \\
\hline 82015 Nov. & 8.5 & L. platyrhincus & LP09 \\
\hline 82015 Nov. & 8.5 & L. platyrhincus & LP10 \\
\hline 82015 Nov. & 8.5 & L. platyrhincus & LP11 \\
\hline 82015 Nov. & 8.5 & L. platyrhincus & LP12 \\
\hline 82015 Nov. & 8.5 & L. platyrhincus & LP13 \\
\hline 82015 Nov. & 8.5 & L. platyrhincus & LP14 \\
\hline 82015 Nov. & 8.5 & L. platyrhincus & LP15 \\
\hline 82015 Nov. & 8.5 & L. platyrhincus & LP16 \\
\hline 82015 Nov. & 8.5 & L. platyrhincus & LP17 \\
\hline 82015 Nov. & 8.5 & L. platyrhincus & LP18 \\
\hline 82015 Nov. & 8.5 & L. platyrhincus & LP19 \\
\hline 82015 Nov. & 8.5 & L. platyrhincus & LP20 \\
\hline 92016 Sept. & 7.9 & L. platyrhincus & LP21 \\
\hline 92016 Sept. & 7.9 & L. platyrhincus & LP22 \\
\hline 92016 Sept. & 7.9 & L. platyrhincus & LP23 \\
\hline 92016 Sept. & 7.9 & L. platyrhincus & LP24 \\
\hline 92016 Sept. & 7.9 & L. platyrhincus & LP25 \\
\hline 92016 Sept. & 7.9 & L. platyrhincus & LP26 \\
\hline 92016 Oct. & 7.9 & L. platyrhincus & LP27 \\
\hline 92016 Oct. & 7.9 & L. platyrhincus & LP28 \\
\hline 92016 Oct. & 7.9 & L. platyrhincus & LP29 \\
\hline 92016 Oct. & 7.9 & L. platyrhincus & LP30 \\
\hline 92016 Oct. & 7.9 & L. platyrhincus & LP31 \\
\hline 92016 Oct. & 7.9 & L. platyrhincus & LP32 \\
\hline 92016 Oct. & 7.9 & L. platyrhincus & LP33 \\
\hline 92016 Oct. & 7.9 & L. platyrhincus & LP34 \\
\hline 92016 Oct. & 7.9 & L. platyrhincus & LP35 \\
\hline 92016 Oct. & 7.9 & L. platyrhincus & LP36 \\
\hline 92016 Oct. & 7.9 & L. platyrhincus & LP37 \\
\hline 92016 Oct. & 7.9 & L. platyrhincus & LP38 \\
\hline
\end{tabular}

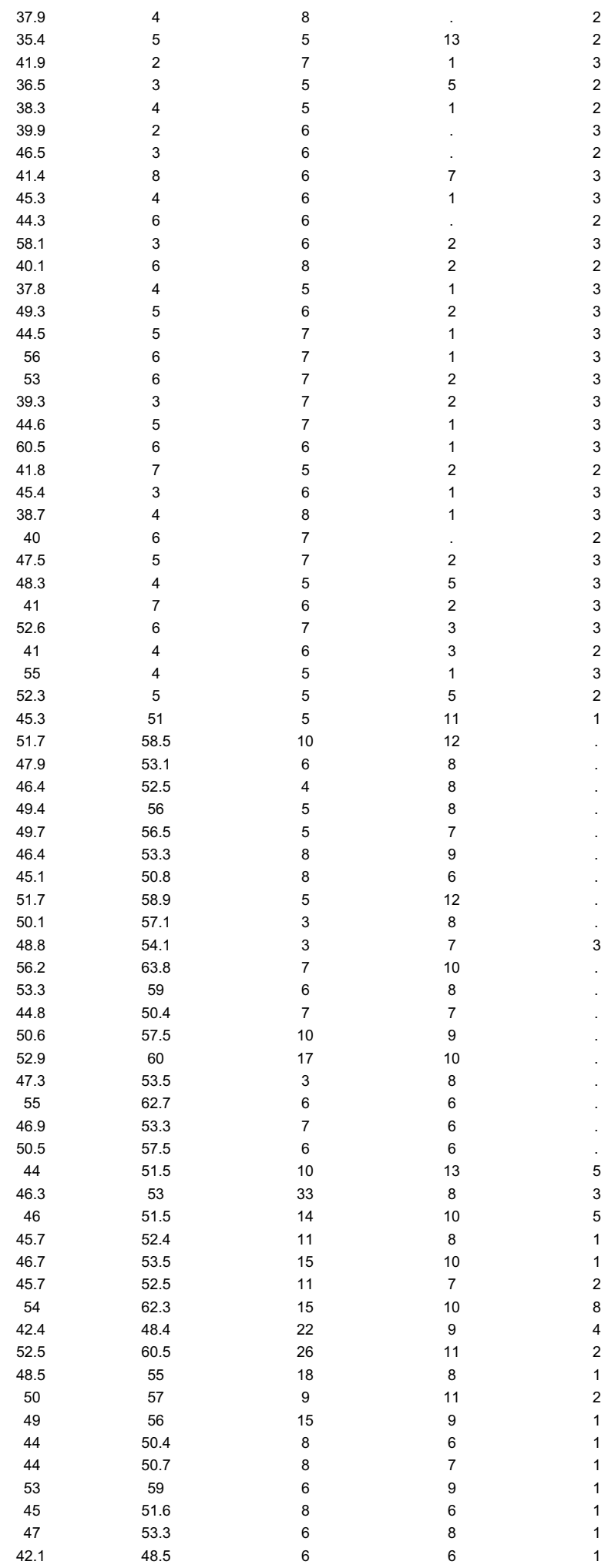


Appendix (continued)

92016 Oct.

$\begin{array}{llll}7.9 & \text { L. platyrhincus } & \text { LP39 } & 41.7\end{array}$

92016 Oct.

$\begin{array}{lll}\text { L. platyrhincus } & \text { LP39 } & 41.7 \\ \text { L. platyrhincus } & \text { LP40 } & 44.3\end{array}$

47

9
5

$\begin{array}{ll}7 & 1 \\ 8 & 1\end{array}$ 